\title{
"Anti-Michael" and Michael Additions in the Reactions of 2-Arylmethyliden-1,3-Indandiones with 2-Aminothiophenol
}

\author{
Jessica J. Sánchez García1, Alberto D. Hernández-Suzan', Elena Martínez-Klimova1, \\ Marcos Flores-Alamo1, Teresa Ramírez Apan², Elena I. Klimova ${ }^{1 *}$ \\ ${ }^{1}$ Departamento de Química Orgánica, Universidad Nacional Autónoma de México, Facultad de Química, Cd. Universitaria, \\ Ciudad de México, México \\ ${ }^{2}$ Instituto de Química, Universidad Nacional Autónoma de México, Facultad de Química, Cd. Universitaria, Ciudad de México, \\ México \\ Email: *eiklimova@yahoo.com.mx
}

How to cite this paper: García, J.J.S., Hernández-Suzan, A.D., Martínez-Klimova, E., Flores-Alamo, M., Apan, T.R. and Klimova, E.I. (2017) “Anti-Michael” and Michael Additions in the Reactions of 2-Arylmethyliden-1,3-Indandiones with 2Aminothiophenol. International Journal of Organic Chemistry, 7, 57-81.

https://doi.org/10.4236/ijoc.2017.71006

Received: October 25, 2016

Accepted: March 12, 2017

Published: March 15, 2017

Copyright (c) 2017 by authors and Scientific Research Publishing Inc. This work is licensed under the Creative Commons Attribution International License (CC BY 4.0).

http://creativecommons.org/licenses/by/4.0/

c) $\underset{\mathrm{EY}}{ }$ Open Access

\begin{abstract}
A novel 2-indano[2,3b]-2-ferrocenyl- and 2-indano[2,3b]-2-(p-methoxyphenyl) [1,5]benzo-2,5-dihydrothiazepine $\mathbf{5 a}, \mathbf{b}$ (addition Michael/cyclization) ( $30.32 \%)$, indano[2,3b]-2-ferrocenyl- and 2-( $p$-methoxyphenyl)[1,4] benzothiazine 4a,b (addition "anti-Michael"/cyclization) ( 45.43\%), respectively, were obtained by the condensation of 2 -ferrocenyl-and 2-( $p$-methoxyphenyl)methyliden-1,3-indandiones $1 \mathrm{a}, \mathrm{b}$ with $o$-aminothiophenol 2 in the presence of $\mathrm{AcOH}$ and $\mathrm{HCl}$. A new "anti-Michael" addition reaction of 1,4bis-heteronucleophile 2 into 2-arylmethyliden-1,3-indandiones was reported. As a result of this reaction the product $1 \mathbf{a}, \mathbf{b}$ was obtained. The structures of the resultant compounds were elucidated by IR, ${ }^{1} \mathrm{H}$ and ${ }^{13} \mathrm{C}$ NMR spectroscopy, mass spectrometry, elemental and X-ray diffraction analysis. The in vitro antitumor activity of the obtained products was researched using the following human cancer cell lines: glioblastoma (CNS U-251), prostatic adenocarcinoma (PC-3), chronic myelogenous leukemia (K562), colorectal adenocarcinoma (HCT-15), mammary adenocarcinoma (MCF-7), and small cell lung cancer (SKLU) and the sulforhodamine B (SRB) method. Among these new compounds some thiazine and thiazepine derivatives showed compelling in vitro antitumor effects on cell lines K-562, HCT-15, SKLU-1 and MCF-7.
\end{abstract}

\section{Keywords}

Ferrocene, Addition "Anti-Michael”, Reaction Cyclization, 1,5-Thiazepines, 1,4-Thiazines, Antitumor Cell Lines

\section{Introduction}

The common strategy for the construction of the 1,5-benzothiazepine moiety is 
the reaction of 1,3-diarylprop-2-enones with $o$-aminothiophenol or 1,3-difunctional three-carbon building blocks. Among them, $\alpha, \beta$-unsaturated carbonyl compounds such as 1,2-enones and 1,2-ynones are best suited for Michael addition and subsequent cyclocondensation [1]. The various reported methodologies involve the use of inorganic supports such as alumina, silica gel, $\mathrm{AcOH}$, trifluoroacetic acid, $\mathrm{HCl}$, piperidine, $\mathrm{BF}_{3} \mathrm{Et}_{2} \mathrm{O}$, etc. to improve the reaction efficiency [2] [3] [4]. Likewise, the related 1,5-benzothiazepines display a comparable spectrum of biological activity. The 1,5-benzothiazepine framework has been identified as a pluripotent pharmacophore with derivatives encompassing CNSacting agents [5], anti-HIV [6], anti-tuberculosis (TB) [7], anticancer drugs [8], antimicrobial [9], calmodulin antagonists [4], enzyme inhibitors [11], antifungal [4] [10], antibacterial [12], anti-inflammatory and analgesic agents [4]. Also, it is expected that new active benzo-1,5-thiazepines and other related derivatives could be used in the treatment of serious human diseases like Alzheimer's diabetes [4].

Ferrocene compounds are known to possess many chemotherapeutic properties [13]. The incorporation of a ferrocenyl-substituent into a benzo-1,5-thiazepine molecule will expand the spectrum of valuable characteristics. Ferrocenylsubstituted 1,5-benzothiazepines have not been extensively studied. The first synthesis of 2-ferrocenyl-4-(4-chlorophenyl)-1,5-benzothiazepine on the base of 1-(4-chlorophenyl)-3-ferrocenyl-2-propenone was reported in 2010 by Willy and Müller [14]. Recently, in 2015, Klimova et al. have published the synthesis of various 2- and 4-ferrocenyl-1,5-benzothiazepines as well as their spectroscopic and structural characteristics [15]. However, The use of 2-ferrocenyl-methyliden-1,3-diones in the synthesis of polycyclic systems with seven-membered heterocycles, such as dihydro-1,5-benzothiazepines and 1,5-benzothiaze-pines, has not been described until now. Therefore, the synthesis of polycyclic ferrocenyl-1,5-benzothiazepines has received considerable attention.

As a continuation of our previous investigations [15] in this field, the present work examines the possibility of synthesizing tetracyclic ferrocenyldihydro1,5-benzothiazepines starting from 2-ferrocenyl- and 2-anisylmethyliden-1,3indandiones $1 \mathrm{a}, \mathrm{b}$ and $o$-aminothiophenol 2 in the presence of acetic or hydrochloric acid.

\section{Material and Methods}

\subsection{Chemistry}

Solvents and reagents were purchased from Aldrich and used without further purification. Column chromatography was carried out on alumina (Brockmann activity III). The ${ }^{1} \mathrm{H}$ and ${ }^{13} \mathrm{C}$ NMR spectra were recorded on a Unity Inova Varian spectrometer $\left(300\right.$ and $75 \mathrm{MHz}$ ) for solutions in $\mathrm{CDCl}_{3}$ with $\mathrm{Me}_{4} \mathrm{Si}$ as the internal standard. The IR spectra were measured with an FTIR spectrophotometer (Spectrum RXI Perkin-Elmer instruments) using $\mathrm{KBr}$ pellets. The mass spectra were obtained on a Varian MAT CH-6 instrument (EI MS, 70 eV). Elementar Analysensysteme LECO CHNS-900 was used for elemental analyses. The fol- 
lowing reagents were purchased from Aldrich: ferrocenecarbaldehyde, 99\%; p-anisaldehyde, 98\%; 1,3-indandione, 97\%; 2-aminothiophenol, 99\%.

For general information, all experimental data, and copies of the NMR spectra and UV/Vis spectra, see the Supporting Information.

Condensation of 2-arylmethylidene-1,3-indandiones (1a,b) with 2-aminothiophenol (2). Tipical Procedure [16]. A mixture of the chalcones (2.5 $\mathrm{mmol})$, 2-aminothiophenol (0.5 g, $4 \mathrm{mmol}), \mathrm{AcOH}(0.5 \mathrm{~mL}), \mathrm{HCl}$ conc. $(0.1 \mathrm{ml})$, $\mathrm{Et}_{3} \mathrm{~N}(0.1 \mathrm{~mL})$ in methanol $(50 \mathrm{~mL})$ was heated to reflux $\left(\sim 60^{\circ} \mathrm{C}-65^{\circ} \mathrm{C}\right)$ and stirred until complete dissolution of the enones $1 \mathrm{a}, \mathrm{b}$ occurred $(\sim 6-8 \mathrm{~h})$. The organic layer was concentrated, and the residue was chromatographed on alumina (Brockmann activity III, hexane-ether, 3:1) to give 2-arylthiazoles 3a,b ( 9\% - 11\%) [17] [18] [19], ferrocenyl- and anisylthiazines 4a,b (43\% - 45\%), ferrocenyl-and anisylthiazapines $5 \mathrm{a}, \mathrm{b}$ (30\% - 32\%), and indeno[2,1-b:2,3-b]bis $[[1,4]$ benzothiazine $6(\sim 10 \%)$.

2-Ferrocenylbenzothiazole (3a): Orange crystals: Yield $0.14 \mathrm{~g}$ (9\%); mp $111^{\circ} \mathrm{C}-112^{\circ} \mathrm{C}$ (lit. [17] mp $112^{\circ} \mathrm{C}$ ). ${ }^{1} \mathrm{H}$ NMR (300 MHz, $\left.\mathrm{CDCl}_{3}, \mathrm{TMS}\right): \delta=4.14$ $\left(\mathrm{s}, 5 \mathrm{H}, \mathrm{C}_{5} \mathrm{H}_{5}\right), 4.48\left(\mathrm{~m}, 2 \mathrm{H}, \mathrm{C}_{5} \mathrm{H}_{4}\right), 4.99\left(\mathrm{~m}, 2 \mathrm{H}, \mathrm{C}_{5} \mathrm{H}_{4}\right), 7.33(\mathrm{td}, 1 \mathrm{H}, \mathrm{J}=1.2,8.1$ $\left.\mathrm{Hz}, o-\mathrm{C}_{6} \mathrm{H}_{4}\right), 7.43\left(\mathrm{td}, 1 \mathrm{H}, \mathrm{J}=1.2,8.1 \mathrm{~Hz}, o-\mathrm{C}_{6} \mathrm{H}_{4}\right), 7.80(\mathrm{~d}, 1 \mathrm{H}, \mathrm{J}=8.1 \mathrm{~Hz}$, $\left.o-\mathrm{C}_{6} \mathrm{H}_{4}\right), 7.95\left(\mathrm{~d}, 1 \mathrm{H}, \mathrm{J}=8.1 \mathrm{~Hz}, o-\mathrm{C}_{6} \mathrm{H}_{4}\right) \mathrm{ppm}$. MS (EI, $\left.70 \mathrm{eV}\right) \mathrm{m} / \mathrm{z} 319[\mathrm{M}]^{+}$. Anal calcd for $\mathrm{C}_{17} \mathrm{H}_{13}$ FeNS: C, 64.00; H, 4.10; N, 4.40; S, 10.00; Found: C, 63.89; $\mathrm{H}, 4.26 ; \mathrm{N}, 4.31 ; \mathrm{S}, 9.84$.

Indano[2,3b]-2-ferrocenylmethyl[1,4]benzothiazine (4a): Orange crystals: Yield $1.02 \mathrm{~g}(45 \%) ; \mathrm{mp} 163^{\circ} \mathrm{C}-164^{\circ} \mathrm{C}$, IR (KBr): $v=467,481,511,729,762,812$, 887, 999, 1042, 1104, 1163, 1216, 1250, 1344, 1441, 1450, 1552, 1599, 1629, 1718, 2944, 3052, $3081 \mathrm{~cm}^{-1}$. ${ }^{1} \mathrm{H}$ NMR (300 MHz, CDCl 3 , TMS): $\delta=2.81(\mathrm{~d}, 1 \mathrm{H}, \mathrm{J}=$ $\left.13.8 \mathrm{~Hz}, \mathrm{CH}_{2}\right), 3.00\left(\mathrm{~d}, 1 \mathrm{H}, \mathrm{J}=13.8 \mathrm{~Hz}, \mathrm{CH}_{2}\right), 3.92\left(\mathrm{~s}, 5 \mathrm{H}, \mathrm{C}_{5} \mathrm{H}_{5}\right), 3.68(\mathrm{~m}, 1 \mathrm{H}$, $\left.\mathrm{C}_{5} \mathrm{H}_{4}\right), 3.71\left(\mathrm{~m}, 1 \mathrm{H}, \mathrm{C}_{5} \mathrm{H}_{4}\right), 3.75\left(\mathrm{~m}, 1 \mathrm{H}, \mathrm{C}_{5} \mathrm{H}_{4}\right), 3.76\left(\mathrm{~m}, 1 \mathrm{H}, \mathrm{C}_{5} \mathrm{H}_{4}\right), 7.20(\mathrm{td}, 1$ $\left.\mathrm{H}, \mathrm{J}=1.2,7.2 \mathrm{~Hz}, \mathrm{C}_{6} \mathrm{H}_{4}\right), 7.30\left(\mathrm{dd}, \mathrm{J}=1.2,7.8 \mathrm{~Hz}, 1 \mathrm{H}, \mathrm{C}_{6} \mathrm{H}_{4}\right), 7.42(\mathrm{td}, 1 \mathrm{H}, \mathrm{J}=$ $\left.1.2,7.8 \mathrm{~Hz}, \mathrm{C}_{6} \mathrm{H}_{4}\right), 7.53\left(\mathrm{td}, 1 \mathrm{H}, \mathrm{J}=1.2,7.2 \mathrm{~Hz}, \mathrm{C}_{6} \mathrm{H}_{4}\right), 7.64(\mathrm{dd}, 1 \mathrm{H}, \mathrm{J}=1.2,7.8$ $\left.\mathrm{Hz}, \mathrm{C}_{6} \mathrm{H}_{4}\right), 7.69\left(\mathrm{dd}, 1 \mathrm{H}, \mathrm{J}=1.2,7.2 \mathrm{~Hz}, \mathrm{C}_{6} \mathrm{H}_{4}\right), 7.76(\mathrm{dd}, 1 \mathrm{H}, \mathrm{J}=1.2,7.2 \mathrm{~Hz}$, $\left.\mathrm{C}_{6} \mathrm{H}_{4}\right), 8.02\left(\mathrm{dd}, 1 \mathrm{H}, \mathrm{J}=1.2,7.8 \mathrm{~Hz}, \mathrm{C}_{6} \mathrm{H}_{4}\right)$ ppm. ${ }^{13} \mathrm{C} \mathrm{NMR}\left(75 \mathrm{MHz}, \mathrm{CDCl}_{3}\right.$, TMS): $\delta=49.25\left(\mathrm{CH}_{2}\right), 68.51\left(\mathrm{C}_{5} \mathrm{H}_{5}\right), 67.75,67.71,69.26,69.51\left(\mathrm{C}_{5} \mathrm{H}_{4}\right), 80.21$ $\left(\mathrm{C}_{\text {ipsofc }}\right), 123.51,123.30,126.93,127.08,128.16,128.93,135.83,138.30\left(2 \mathrm{C}_{6} \mathrm{H}_{4}\right)$, 62.12, 122.52, 129.64, 132.58, 142.93, $145.31(6 \mathrm{C}), 160.19(\mathrm{C}=\mathrm{N}), 195.50(\mathrm{C}=\mathrm{O})$ ppm. MS (EI, $70 \mathrm{eV}): \mathrm{m} / \mathrm{z} 449[\mathrm{M}]^{+}$. Anal calcd. for $\mathrm{C}_{26} \mathrm{H}_{19} \mathrm{FeNOS}$; C, 69.51; $\mathrm{H}$, 4.26; N, 3.12; S, 7.12; Found: C, 69.29; H, 4.34; N, 3.27; S, 7.03.

2-Indeno[2,3b]-2-ferrocenyl[1,5]benzo-2,5-dihydro-thiazepine (5a): Orange crystals: Yield $0.68 \mathrm{~g}(30 \%) ; \mathrm{mp} 184^{\circ} \mathrm{C}-185^{\circ} \mathrm{C}$, IR $(\mathrm{KBr}): v=481,497$, 507, 733, 761, 817, 893, 1003, 1078, 1105, 1179, 1212, 1224, 1358, 1376, 1429, $1454,1478,1540,1578,1594,1619,1681,1701,1735,3008,3187,3361 \mathrm{~cm}^{-1} .{ }^{1} \mathrm{H}$ $\operatorname{NMR}\left(300 \mathrm{MHz}, \mathrm{CDCl}_{3}, \mathrm{TMS}\right): \delta=4.16\left(\mathrm{~s}, 5 \mathrm{H}, \mathrm{C}_{5} \mathrm{H}_{5}\right), 3.41\left(\mathrm{~m}, 1 \mathrm{H}, \mathrm{C}_{5} \mathrm{H}_{4}\right), 3.74$ $\left(\mathrm{m}, 1 \mathrm{H}, \mathrm{C}_{5} \mathrm{H}_{4}\right), 4.00\left(\mathrm{~m}, 1 \mathrm{H}, \mathrm{C}_{5} \mathrm{H}_{4}\right), 4.26\left(\mathrm{~m}, 1 \mathrm{H}, \mathrm{C}_{5} \mathrm{H}_{4}\right), 5.41(\mathrm{~s}, 1 \mathrm{H}, \mathrm{CH}), 6.94$ $\left(\mathrm{td}, 1 \mathrm{H}, \mathrm{J}=1.2,7.5 \mathrm{~Hz}, \mathrm{C}_{6} \mathrm{H}_{4}\right), 7.09\left(\mathrm{dd}, \mathrm{J}=1.2,7.8 \mathrm{~Hz}, 1 \mathrm{H}, \mathrm{C}_{6} \mathrm{H}_{4}\right), 7.16(\mathrm{dd}, 1$ $\left.\mathrm{H}, \mathrm{J}=1.2,7.8 \mathrm{~Hz}, \mathrm{C}_{6} \mathrm{H}_{4}\right), 7.27\left(\mathrm{td}, 1 \mathrm{H}, \mathrm{J}=1.2,7.8 \mathrm{~Hz}, \mathrm{C}_{6} \mathrm{H}_{4}\right), 7.33(\mathrm{td}, 1 \mathrm{H}, \mathrm{J}=$ 
$\left.1.2,7.5 \mathrm{~Hz}, \mathrm{C}_{6} \mathrm{H}_{4}\right), 7.38\left(\mathrm{dd}, 1 \mathrm{H}, \mathrm{J}=1.2,7.5 \mathrm{~Hz}, \mathrm{C}_{6} \mathrm{H}_{4}\right), 7.42(\mathrm{td}, 1 \mathrm{H}, \mathrm{J}=1.2,7.8$ $\left.\mathrm{Hz}, \mathrm{C}_{6} \mathrm{H}_{4}\right), 7.48$ (bs, $\left.1 \mathrm{H}, \mathrm{NH}\right), 7.56\left(\mathrm{dd}, 1 \mathrm{H}, \mathrm{J}=1.2,7.8 \mathrm{~Hz}, \mathrm{C}_{6} \mathrm{H}_{4}\right) \mathrm{ppm} .{ }^{13} \mathrm{C}$ NMR (75 MHz, $\mathrm{CDCl}^{3}$, TMS): $\delta=42.56(\mathrm{CH}), 68.93\left(\mathrm{C}_{5} \mathrm{H}_{5}\right), 66.11,67.04,67.15$, $68.05\left(\mathrm{C}_{5} \mathrm{H}_{4}\right), 91.11\left(\mathrm{C}_{\mathrm{ipsoFc}}\right), 115.46,121.38,121.76,124.78,128.65,130.27$, 131.34, 136.94 (2 C6H4), 147.66, 152.69, 154.55, 156.08, 172.44, 178.08 (6 C), $181.45(\mathrm{C}=\mathrm{O}) \mathrm{ppm}$. MS (EI, $70 \mathrm{eV}): \mathrm{m} / \mathrm{z} 449[\mathrm{M}]^{+}$. Anal calcd. for $\mathrm{C}_{26} \mathrm{H}_{19} \mathrm{FeNOS}$ : C, 69.51; H, 4.26; N, 3.12; S, 7.12; Found: C, 69.04; H, 4.95; N, 3.54; S, 7.15.

2-(p-Methoxyphenyl)benzothiazole (3b): Yellow crystals: Yield $0.13 \mathrm{~g}$ (11\%); mp $120^{\circ} \mathrm{C}-122^{\circ} \mathrm{C}$ (lit. [18] $\mathrm{mp} 120^{\circ} \mathrm{C}$ ). ${ }^{1} \mathrm{H}$ NMR (300 $\mathrm{MHz}, \mathrm{CDCl}_{3}$, TMS): $\delta=3.86\left(\mathrm{~s}, 3 \mathrm{H}, \mathrm{CH}_{3}\right), 6.97\left(\mathrm{~d}, 2 \mathrm{H}, \mathrm{J}=9.0 \mathrm{~Hz}, p-\mathrm{C}_{6} \mathrm{H}_{4}\right), 7.34(\mathrm{t}, \mathrm{J}=7.5 \mathrm{~Hz}$, $\left.1 \mathrm{H}, o-\mathrm{C}_{6} \mathrm{H}_{4}\right), 7.46\left(\mathrm{t}, 1 \mathrm{H}, \mathrm{J}=8.1 \mathrm{~Hz}, o-\mathrm{C}_{6} \mathrm{H}_{4}\right), 7.85\left(\mathrm{~d}, 1 \mathrm{H}, \mathrm{J}=7.5 \mathrm{~Hz}, o-\mathrm{C}_{6} \mathrm{H}_{4}\right)$, $8.01\left(\mathrm{~d}, 1 \mathrm{H}, \mathrm{J}=8.1 \mathrm{~Hz}, o-\mathrm{C}_{6} \mathrm{H}_{4}\right), 8.03 \quad\left(\mathrm{~d}, 2 \mathrm{H}, \mathrm{J}=9.0 \mathrm{~Hz}, p-\mathrm{C}_{6} \mathrm{H}_{4}\right) \mathrm{ppm}$. MS $(\mathrm{EI}, 70 \mathrm{eV}): \mathrm{m} / \mathrm{z} 241[\mathrm{M}]^{+}$. Anal calcd for $\mathrm{C}_{14} \mathrm{H}_{11} \mathrm{NOS}$ : C, 69.70; H, 4.60; N, 5.80; S, 13.26; Found: C, 69.58; H, 4.81; N, 5.63; 13.04 .

Indano[2,3b]-2-[(p-methoxyphenyl)methyl][1,4]benzothiazine (4b): Yellow crystals: Yield $0.40 \mathrm{~g}(43 \%) ; \mathrm{mp} 109^{\circ} \mathrm{C}-110^{\circ} \mathrm{C}$, IR (KBr): $v=467,481,511$, 729, 762, 812, 887, 999, 1042, 1104, 1163, 1216, 1250, 1344, 1441, 1450, 1552, $1599,1629,1718,2944,3052,3081 \mathrm{~cm}^{-1} .{ }^{1} \mathrm{H}$ NMR $\left(300 \mathrm{MHz}, \mathrm{CDCl}_{3}, \mathrm{TMS}\right): \delta=$ $2.96\left(\mathrm{~d}, 1 \mathrm{H}, \mathrm{J}=13.5 \mathrm{~Hz}, \mathrm{CH}_{2}\right), 3.13\left(\mathrm{~d}, 1 \mathrm{H}, \mathrm{J}=13.5 \mathrm{~Hz}, \mathrm{CH}_{2}\right), 3.62(\mathrm{~s}, 3 \mathrm{H}$, $\left.\mathrm{CH}_{3}\right), 6.53\left(\mathrm{~d}, 2 \mathrm{H}, \mathrm{J}=8.7 \mathrm{~Hz}, p-\mathrm{C}_{6} \mathrm{H}_{4}\right), 6.75\left(\mathrm{~d}, 2 \mathrm{H}, \mathrm{J}=8.7 \mathrm{~Hz}, p-\mathrm{C}_{6} \mathrm{H}_{4}\right), 7.21(\mathrm{t}$, $\left.\mathrm{J}=7.5 \mathrm{~Hz}, 1 \mathrm{H}, o-\mathrm{C}_{6} \mathrm{H}_{4}\right), 7.35\left(\mathrm{t}, 1 \mathrm{H}, \mathrm{J}=8.1 \mathrm{~Hz}, o-\mathrm{C}_{6} \mathrm{H}_{4}\right), 7.44(\mathrm{~d}, 1 \mathrm{H}, \mathrm{J}=7.5$ $\left.\mathrm{Hz}, o-\mathrm{C}_{6} \mathrm{H}_{4}\right), 7.53\left(\mathrm{~d}, 1 \mathrm{H}, \mathrm{J}=8.1 \mathrm{~Hz}, o-\mathrm{C}_{6} \mathrm{H}_{4}\right), 7.66(\mathrm{t}, 1 \mathrm{H}, \mathrm{J}=7.5 \mathrm{~Hz}, o-$ $\left.\mathrm{C}_{6} \mathrm{H}_{4}\right), 7.69\left(\mathrm{t}, 1 \mathrm{H}, \mathrm{J}=7.5 \mathrm{~Hz}, o-\mathrm{C}_{6} \mathrm{H}_{4}\right), 7.72\left(\mathrm{~d}, 1 \mathrm{H}, \mathrm{J}=7.8 \mathrm{~Hz}, o-\mathrm{C}_{6} \mathrm{H}_{4}\right), 8.01(\mathrm{~d}$, $\left.1 \mathrm{H}, \mathrm{J}=7.8 \mathrm{~Hz}, o-\mathrm{C}_{6} \mathrm{H}_{4}\right) \mathrm{ppm} .{ }^{13} \mathrm{C} \mathrm{NMR}\left(75 \mathrm{MHz}, \mathrm{CDCl}_{3}, \mathrm{TMS}\right): \delta=39.43\left(\mathrm{CH}_{2}\right)$, $55.11\left(\mathrm{CH}_{3}\right), 113.37,130.66\left(p-\mathrm{C}_{6} \mathrm{H}_{4}\right), 123.28,123.49,127.05,127.26,128.05$, 129.14, 132.77, $136.08\left(2 o-\mathrm{C}_{6} \mathrm{H}_{4}\right), 49.52,122,75,125.91,138.21,143.09,145.20$, 158.54, $159.87(8 \mathrm{C}), 199.38(\mathrm{C}=\mathrm{O})$ ppm. MS (EI, $70 \mathrm{eV}): \mathrm{m} / \mathrm{z} 372[\mathrm{M}]^{+}$. Anal calcd for $\mathrm{C}_{23} \mathrm{H}_{17} \mathrm{NO}_{2} \mathrm{~S}$ : C, 74.38; H, 4.62; N, 3.77; S, 8.62; Found: C, 74.21; H, 4.74; $\mathrm{N}, 3.56 ; \mathrm{S}, 8.93$.

\section{2-Indeno[2,3b]-2-(p-methoxyphenyl) [1,5]benzo-2,5-dihydrothiazepine}

(5b): Orange crystals: Yield $0.30 \mathrm{~g}(32 \%) ; \mathrm{mp} 126^{\circ} \mathrm{C}-127^{\circ} \mathrm{C}$, IR (KBr): $v=481$, 496, 622, 760, 892, 980, 1078, 1105, 1179, 1212, 1224, 1357, 1454, 1478, 1538, $1577,1593,1619,1680,1701,3055,3186,3361 \mathrm{~cm}^{-1} .{ }^{1} \mathrm{H}$ NMR $\left(300 \mathrm{MHz}, \mathrm{CDCl}_{3}\right.$, TMS): $\delta=4.55$ (s, $3 \mathrm{H}, \mathrm{CH}_{3}$ ), $6.05(\mathrm{~s}, 1 \mathrm{H}, \mathrm{CH}), 6.97\left(\mathrm{~d}, 2 \mathrm{H}, \mathrm{J}=9.0 \mathrm{~Hz}, p-\mathrm{C}_{6} \mathrm{H}_{4}\right.$ ), $8.02\left(\mathrm{~d}, 2 \mathrm{H}, \mathrm{J}=9.0 \mathrm{~Hz}, p-\mathrm{C}_{6} \mathrm{H}_{4}\right), 6.59\left(\mathrm{td}, 1 \mathrm{H}, \mathrm{J}=1.5,7.5 \mathrm{~Hz}, o-\mathrm{C}_{6} \mathrm{H}_{4}\right), 6.69(\mathrm{dd}$, $\left.1 \mathrm{H}, \mathrm{J}=1.2,7.5 \mathrm{~Hz}, o-\mathrm{C}_{6} \mathrm{H}_{4}\right), 7.13\left(\mathrm{~m}, 3 \mathrm{H}, o-\mathrm{C}_{6} \mathrm{H}_{4}\right), 7.36(\mathrm{td}, 1 \mathrm{H}, \mathrm{J}=1.2,7.8 \mathrm{~Hz}$, $\left.o-\mathrm{C}_{6} \mathrm{H}_{4}\right), 7.46\left(\mathrm{td}, 1 \mathrm{H}, \mathrm{J}=1.5,7.5 \mathrm{~Hz}, \mathrm{C}_{6} \mathrm{H}_{4}\right), 7.82(\mathrm{bs}, 1 \mathrm{H}, \mathrm{NH}), 7.84(\mathrm{dd}, 1 \mathrm{H}, \mathrm{J}$ $\left.=1.2,7.8 \mathrm{~Hz}, o-\mathrm{C}_{6} \mathrm{H}_{4}\right) \mathrm{ppm} .{ }^{13} \mathrm{C} \mathrm{NMR}\left(75 \mathrm{MHz}, \mathrm{CDCl}_{3}, \mathrm{TMS}\right): \delta=53,12(\mathrm{CH})$, $58.24\left(\mathrm{CH}_{3}\right), 119.72,136.44\left(p-\mathrm{C}_{6} \mathrm{H}_{4}\right), 122.76,123.82,128.02,128.76,131.87$, 133.04, 135.16, $137.52\left(2 o-\mathrm{C}_{6} \mathrm{H}_{4}\right), 122,98,124.06,136.23,138.91,141.21,144.63$, 148.36, $155.17(8 \mathrm{C}), 197.34(\mathrm{C}=\mathrm{O})$ ppm. MS (EI, $70 \mathrm{eV}): \mathrm{m} / \mathrm{z} 371[\mathrm{M}]^{+}$. Anal calcd for $\mathrm{C}_{23} \mathrm{H}_{17} \mathrm{NO}_{2} \mathrm{~S}: \mathrm{C}, 74.38 ; \mathrm{H}, 4.62 ; \mathrm{N}, 3.77 ; \mathrm{S}, 8.62$. Found: C, 74.56; H, 4.43; $\mathrm{N}, 3.89 ; \mathrm{S}, 8.54$.

Indano[2,1-b:2,3-b] bis[[1,4]benzothiazine (6): Yellow crystals: Yield $0.32 \mathrm{~g}$ 
(10\%); mp $200^{\circ} \mathrm{C}-201^{\circ} \mathrm{C}$ (lit.[19]mp $\left.201^{\circ} \mathrm{C}-203^{\circ} \mathrm{C}\right) . \mathrm{IR}(\mathrm{KBr}): v=635,738$, $755,985,1174,1218,1246,1269,1329,1351,1460,1562,1606,1667,1682,3064$, $3111 \mathrm{~cm}^{-1}$. 1H NMR (300 MHz, $\left.\mathrm{CDCl}_{3}, \mathrm{TMS}\right): \delta=7.35-8.10(\mathrm{~m}, 12 \mathrm{H}, 3$ $\left.o-\mathrm{C}_{6} \mathrm{H}_{4}\right) \cdot{ }^{13} \mathrm{C} \mathrm{NMR}\left(75 \mathrm{MHz}, \mathrm{CDCl}_{3}, \mathrm{TMS}\right): \delta=56.21\left(\mathrm{C}_{\text {spiro }}\right), 124.25,124.49$, 127.08, 127.26, 129.85, $130.16\left(3 o-\mathrm{C}_{6} \mathrm{H}_{4}\right), 125,98,128.84,134.29$ (6 C), 157.86 (2 $\mathrm{C}=\mathrm{N})$ ppm. MS (EI, $70 \mathrm{eV}): \mathrm{m} / \mathrm{z} 356[\mathrm{M}]^{+}$. Anal calcd for $\mathrm{C}_{21} \mathrm{H}_{12} \mathrm{~N}_{2} \mathrm{~S}_{2}: \mathrm{C}, 70.76$; H, 3.39; N, 7.86; S, 17.99; Found: C, 69.40; H, 4.10; N, 8.20; S, 18.30.

Reaction of 1,3-indandione with 2-aminothiophenol 2. This was carried out analogously using of 1,3-indandione (5 mmol), 2-aminothiophenol (12 $\mathrm{mmol})$, methanol $(70 \mathrm{~mL}), \mathrm{AcOH}(1.0 \mathrm{~mL}), \mathrm{HCl}$ conc. $(0.2 \mathrm{~mL})$ and $\mathrm{Et}_{3} \mathrm{~N}(0.2$ $\mathrm{mL})$. The reaction mixture was performed as described above, the precipitate was filtered off and dried on a filter to give $0.85 \mathrm{~g}$ of a yellowish product, subsequent chromatography on $\mathrm{Al}_{2} \mathrm{O}_{3}$ (hexane-dichloromethane, 1:4) gave 2,2-bis-(2-aminophenylthio)indan-1,3-dione 8 . The filtrate was concentrated, and the residue was chromatographed on $\mathrm{Al}_{2} \mathrm{O}_{3}$ (hexane-dichloromethane, 2:1) to give indeno [2,1-b:2,3-b] bis[[1,4]benzothiazine 6, yield $0.73 \mathrm{~g}(41 \%)$, m.p. $201^{\circ} \mathrm{C}$; and 2,2-bis(2-aminophenylthio)indan-1,3-dione 8.

2,2-bis-(2-aminophenylthio)indan-1,3-dione (8): Yellow crystals: Yield $0.67 \mathrm{~g}(34 \%), \mathrm{mp} 178^{\circ} \mathrm{C}-179^{\circ} \mathrm{C}$, IR (KBr): $v=675,742,761,898,943,1181$, $1234,1252,1271,1317,1363,1458,1581,1609,1667,1682,3386,3419 \mathrm{~cm}^{-1} \cdot{ }^{1} \mathrm{H}$ NMR (300 MHz, $\left.\mathrm{CDCl}_{3}, \mathrm{TMS}\right): \delta=4.14\left(\mathrm{~s}, 4 \mathrm{H}, 2 \mathrm{NH}_{2}\right), 7.71-8.02(\mathrm{~m}, 10 \mathrm{H}$, $\left.2 o-\mathrm{C}_{6} \mathrm{H}_{4}+o-\mathrm{C}_{6} \mathrm{H}_{2}\right), 9.66\left(\mathrm{~d}, 2 \mathrm{H}, \mathrm{J}=8.1 \mathrm{~Hz}, o-\mathrm{C}_{6} \mathrm{H}_{2}\right) \cdot \mathrm{MS}(\mathrm{EI}, 70 \mathrm{eV}): \mathrm{m} / \mathrm{z} 392$ $[\mathrm{M}]^{+}$. Anal calcd. for $\mathrm{C}_{21} \mathrm{H}_{16} \mathrm{~N}_{2} \mathrm{O}_{2} \mathrm{~S}_{2}: \mathrm{C}, 64.28 ; \mathrm{H}, 4.11 ; \mathrm{N}, 7.14 ; \mathrm{S}, 16.31$. Found: $\mathrm{C}$, 64.45; H, 4.03; N, 7.29; S, 16.17 .

\subsection{X-Ray Analysis}

Crystals of $4 \mathrm{a}$ and $5 \mathrm{a}$ were obtained by crystallization from dichloromethane; crystals of 6 were obtained by crystallization from chloroform. Data were obtained on an Oxford Diffraction Gemini Adiffractometer with a CCD area detector, and the CrystAlisPro and CrysAlis RED software packages were used for data collection and data integration [20]. The structures were solved using SHELXS-97 [21] and refined by full-matrix least-squares on $\mathrm{F}^{2}$ with SHELXL-97. [22] Weighted R factors, Rw, and all goodness-of-fit indicators, S, were based F2. The observed criterion of $\left(\mathrm{F}^{2}>2 \sigma \mathrm{F}^{2}\right)$ was used only for calculating the $\mathrm{R}$ factors. All non-hydrogen atoms were refined with anisotropic thermal parameters in the final cycles of refinement. Hydrogen atoms were placed in ideal positions, with $\mathrm{C}-\mathrm{H}$ distances of 0.93 and $0.98 \AA$ for aromatic and satured carbon atoms, respectively. The isotropic thermal parameters of the hydrogen atoms were assigned the values of Uiso $=1.2$ times the thermal parameters of the parent nonhydrogen atom.

Crystal data for $\mathrm{C}_{26} \mathrm{H}_{19} \mathrm{FeNOS}(4 \mathrm{a}): \mathrm{M}=449.33$ gmol-1, monoclinic P21/n, a $=7.5018(2), \mathrm{b}=13.2011(5), \mathrm{c}=20.1153(7) \AA, \alpha=90^{\circ}, \beta=93.922(3), \gamma=90^{\circ}, \mathrm{V}$ $=1987.39(12) \AA^{3}, \mathrm{~T}=130(2) \mathrm{K}, \mathrm{Z}=4, \rho=1.502 \mathrm{Mg} / \mathrm{m}^{3}$, wavelength $0.71073 \AA$, $\mathrm{F}(000)=928$, absorption coefficient $0.883 \mathrm{~mm}-1$, index ranges $-8 \leq \mathrm{h} \leq 10,-13$ 
$\leq \mathrm{k} \leq 18,-25 \leq 1 \leq 25$, scan range $3.414^{\circ} \leq \theta \leq 29.589^{\circ}, 4695$ independent reflections, Rint $=0.0273,10332$ total reflections, 271 refinable parameters, final $\mathrm{R}$ indices $[\mathrm{I}>2 \sigma(\mathrm{I})] \mathrm{R}_{1}=0.0331, \mathrm{wR}_{2}=0.0710, \mathrm{R}$ indices (all data) $\mathrm{R}_{1}=0.0468, \mathrm{wR}_{2}$ $=0.0766$, goodness-of-fit on $\mathrm{F}_{2}$ 1.014, largest difference peak and hole 0.353/ $-0.300 \mathrm{e}^{-3}$.

Crystal data for $\mathrm{C}_{26} \mathrm{H}_{19} \mathrm{FeNOS} \cdot \mathrm{CH}_{2} \mathrm{Cl}_{2}(5 \mathrm{a}): \mathrm{M}=534.26 \mathrm{~g} \cdot \mathrm{mol}^{-1}$, monoclinic $\mathrm{P} 21 / \mathrm{n}, \mathrm{a}=11.3274(9), \mathrm{b}=17.8011(11), \mathrm{c}=11.9213(9) \AA, \alpha=90, \beta=109.584$ (9), $\gamma=90^{\circ}, \mathrm{V}=2264.8(3) \AA^{3}, \mathrm{~T}=130(2) \mathrm{K}, \mathrm{Z}=4, \rho=1.567 \mathrm{Mg} / \mathrm{m}^{3}$, wavelength $0.71073 \AA, \mathrm{F}(000)=1096$, absorption coefficient $1.016 \mathrm{~mm}-1$, index ranges -15 $\leq \mathrm{h} \leq 9,-16 \leq \mathrm{k} \leq 24,-16 \leq 1 \leq 16$, scan range $3.628^{\circ} \leq \theta \leq 29.514^{\circ}, 5308$ independent reflections, Rint $=0.0499,10868$ total reflections, 301 refinable parameters, final $\mathrm{R}$ indices $[\mathrm{I}>2 \sigma(\mathrm{I})] \mathrm{R}_{1}=0.0565, \mathrm{wR}_{2}=0.1406, \mathrm{R}$ indices (all data) $\mathrm{R}_{1}=$ $0.0733, w \mathrm{R}_{2}=0.1597$, goodness-of-fit on $\mathrm{F}_{2} 1.052$, largest difference peak and hole $1.401 /-1.182 \mathrm{e}^{-3}$.

Crystal data for $\mathrm{C}_{21} \mathrm{H}_{12} \mathrm{~N}_{2} \mathrm{~S}_{2}(6): \mathrm{M}=356.45 \mathrm{~g} \cdot \mathrm{mol}^{-1}$, monoclinic $\mathrm{C} 2 / \mathrm{c}$, $\mathrm{a}=$ 22.1186(19), $\mathrm{b}=9.4445(6), \mathrm{c}=16.5628(12) \AA, \alpha=92.750(9), \beta=109.546(9), \gamma=$ $90^{\circ}, \mathrm{V}=3260.6(5) \AA^{3}, \mathrm{~T}=130(2) \mathrm{K}, \mathrm{Z}=8, \rho=1.452 \mathrm{Mg} / \mathrm{m}^{3}$, wavelength 0.71073 $\AA, \mathrm{F}(000)=1472$, absorption coefficient $0.332 \mathrm{~mm}^{-1}$, index ranges $-30 \leq \mathrm{h} \leq 20$, $-12 \leq \mathrm{k} \leq 12,-22 \leq 1 \leq 21$, scan range $3.521 \leq \theta \leq 29.469 \mathrm{o}, 3841$ independent reflections, Rint $=0.0334,7716$ total reflections, 226 refinable parameters, final $\mathrm{R}$ indices $[\mathrm{I}>2 \sigma(\mathrm{I})] \mathrm{R} 1=0.0407, \mathrm{wR}_{2}=0.0820, \mathrm{R}$ indices (all data) $\mathrm{R}_{1}=0.0668, \mathrm{wR}_{2}$ $=0.0895$, goodness-of-fit on $\mathrm{F}_{2}$ 1.012, largest difference peak and hole $0.298 /$ $-0.284 \mathrm{e}^{-3}$.

\subsection{Cytotoxicity Assay}

The compounds were screened in vitro against human cancer cell lines HCT-15 (human colorectal adenocarcinoma), MCF-7 (human mammary adenocarcinoma), K562 (human chronic myelogenous leukemia), U251 (human glioblastoma), PC-3 (human prostatic adenocarcinoma), SKLU-1 (human lung adenocarcinoma). The cell lines were supplied by the National Cancer Institute (USA). The human tumor cytotoxicity was determined using the protein-binding dye sulforhodamine B (SRB) in the microculture assay to measure the cell growth, as is described in the protocols established by the NCI [23] [24]. The cell lines were cultured in the RPMI-1640 medium supplemented with $10 \%$ fetal bovine serum, $2 \mathrm{mM}$ L-glutamine, 10,000 units/ml penicillin $\mathrm{G}$ sodium, $10 \mu \mathrm{g} / \mathrm{ml}$ streptomycin sulfate, $25 \mu \mathrm{g} / \mathrm{ml}$ amphotericin B (Gibco) and 1\% non-essential amino acids (Gibco). The cultures were maintained at $37^{\circ} \mathrm{C}$ in a humidified $5 \% \mathrm{CO}_{2}$ atmosphere. As determined using trypan blue, the viability of the cells used in the experiments exceeded $95 \%$.

The cells were removed from the tissue culture flasks by treatment with trypsin and diluted with fresh media. 100-ml cell suspension aliquots, containing 5000 - 10,000 cells per well, were transferred into 96-well microtiter plates (Costar) and incubated at $37^{\circ} \mathrm{C}$ for $24 \mathrm{~h}$ in a $5 \% \mathrm{CO}_{2}$ atmosphere.

Stock solutions of the test compounds initially dissolved in DMSO (20 mM) 
were prepared and further diluted in the medium to produce the desired concentrations. 100-ml aliquots of the diluted solutions of the test compounds were added to each well. The cultures were exposed to the compound at concentrations $50 \mu \mathrm{M}$ for $48 \mathrm{~h}$. After the incubation period, the cells were fixed to a plastic substratum by the addition of $50 \mu \mathrm{l}$ of cold $50 \%$ aqueous trichloroacetic acid. The plates were incubated at $4^{\circ} \mathrm{C}$ for $1 \mathrm{~h}$, washed with tap $\mathrm{H}_{2} \mathrm{O}$, and air-dried. The cells fixed with trichloroacetic acid were stained by the addition of $0.4 \%$ SRB. Free SRB solution was removed by washing with $1 \%$ aqueous acetic acid. The plates were air-dried, and the bound dye was solubilized by the addition of $100 \mu \mathrm{L}$ of $10 \mathrm{Mm}$ un buffered Tris base. The plates were placed on a shaker for 5 min prior to analysis. The optical densities were determined using a Ultra Microplated Reader (Elx 808: Bio-Tek Instruments, Inc., Winooski, VT, USA) at a test wavelength of $515 \mathrm{~nm}$.

\section{Results and Discussion}

\subsection{Chemistry}

The starting compounds $1 \mathrm{a}, \mathrm{b}$ were prepared by condensation of the respective ferrocenyl- and anisylcarbaldehydes with 1,3-indandione under standard conditions [25] [26] [27]. It was found that $o$-aminothiophenol 2 reacted with chalcones $1 \mathrm{a}, \mathrm{b}$ on refluxing condition in methanol in the presence of acetic and hydrochloric acids to give indeno[2,3b]-2-ferrocenylmethyl- and indano[2,3b]-2anisylmethyl[1,4]benzo-2,3-dihydrothiazines $4 \mathrm{a}, \mathrm{b}(\sim 43 \%-45 \%)$, and 2-inde-no [2,3b]-2-ferroceny-and 2-p-anisyl[1,5]benzo-2,5-dihydrothiazepines 5a,b ( 30\% - 32\%), respectively. (Scheme 1)

In all cases, the reactions were accompanied by fragmentation [28] of the starting compounds $1 \mathrm{a}, \mathrm{b}$ to form 2 -ferrocenyl- and 2-anisylbenzothiazoles $3 \mathrm{a}, \mathbf{b}$ $(\sim 8 \%-11 \%)$ [20] [21] respectively, and indano[2,1-b:2,3-b] bis[[1,4]-benzothiazine6 ( 10\%) [19].

The structures of compounds $\mathbf{3 a}, \mathbf{b}, \mathbf{4 a}, \mathbf{b}, \mathbf{5 a}, \mathbf{b}$ and $\mathbf{6}$ were isolated by column chromatography on alumina and established based on the data from IR and NMR spectroscopy, mass spectrometry and elemental analysis (see Experimental part). The ${ }^{1} \mathrm{H}$ NMR spectrum of ferrocenyl-1,4-thiazine $4 \mathrm{a}$ contains two characteristic doublets for two protons of the methylene group $(\delta 2.81,3.00, J=$

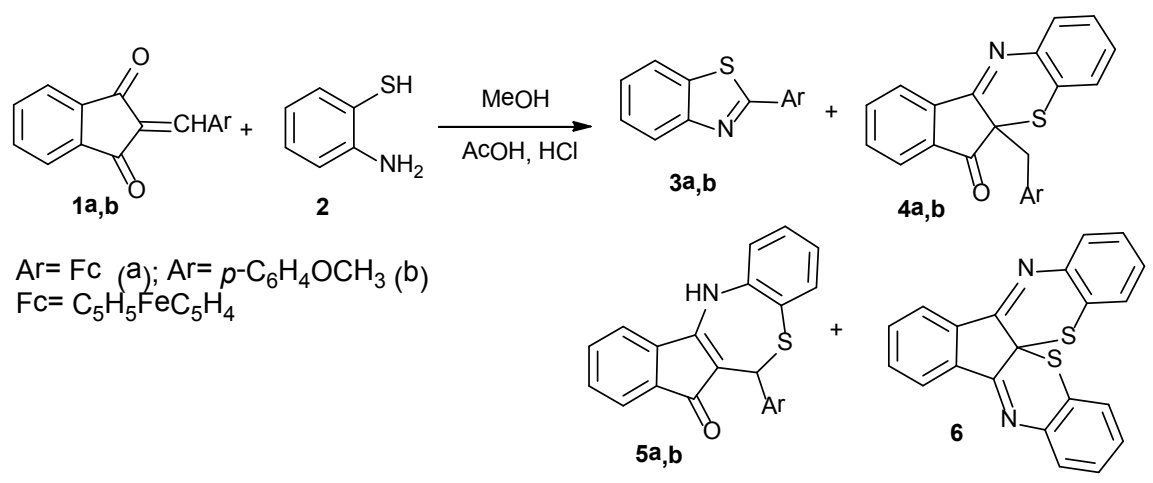

Scheme 1. Reactions of 2-arylmethylidenindan-1,3-dione with o-aminothiophenol. 
13.8 Hz), one singlet for the protons of unsubstituted $\mathrm{C}_{5} \mathrm{H}_{5}$ ring of ferrocene, and multiplets for protons of two $o-\mathrm{C}_{6} \mathrm{H}_{4}$ groups. The presence in the ${ }^{13} \mathrm{C}$ NMR spectrum of compound $4 \mathrm{a}$ of one signal for one methylene group ( $\delta 42.25)$, one ferrocenyl fragment $\left[\delta 68.51\left(\mathrm{C}_{5} \mathrm{H}_{5}\right)\right]$, one $\mathrm{C}_{\mathrm{ipsoFc}}$ carbon atom $(\delta 80.21)$, one $\mathrm{C}=\mathrm{O}$ group $(\delta 195.50)$, one $\mathrm{C}=\mathrm{N}$ fragment $(\delta 160.19)$, and six quaternary carbon atoms $(\delta 62.12,122.52,129.64,132.58,142.93,145.31)$ corroborates completely the suggested structure. The spectroscopic data $\left({ }^{1} \mathrm{H}\right.$ and ${ }^{13} \mathrm{C}$ NMR) suggest that compound $\mathbf{4 b}$ represent also structure of anisyl-1,4-benzothiazine.

The spatial structure of $4 \mathrm{a}$ was elucidated by X-ray diffraction analysis of a single crystal obtained by crystallization from dichloromethane. The general view of the molecule $4 \mathrm{a}$ is shown in Figure 1 and the main geometrical parameters are given in Table 1. Data from X-ray analysis proved the structure of $4 \mathrm{a}$ as indano[2,3b]-2-ferrocenylmethyl[1,4]benzothiazines.

Table 1. Selected bond lengths and bond angles for compounds $\mathbf{4 a}, \mathbf{5 a}$ and $\mathbf{6}$.

\begin{tabular}{|c|c|c|c|}
\hline \multicolumn{2}{|c|}{ Selected bond lengths $(\AA)$} & \multicolumn{2}{|c|}{ Selected bond angles $\left({ }^{\circ}\right)$} \\
\hline \multicolumn{4}{|c|}{$4 a$} \\
\hline $\mathrm{O}(1)-\mathrm{C}(13)$ & $1.214(2)$ & $\mathrm{N}(1)-\mathrm{C}(20)-\mathrm{C}(12)$ & $126.73(16)$ \\
\hline$S(1)-C(26)$ & $1.768(18)$ & $\mathrm{C}(20)-\mathrm{N}(1)-\mathrm{C}(21)$ & $118.65(15)$ \\
\hline $\mathrm{N}(2)-\mathrm{C}(21)$ & $1.413(2)$ & $C(26)-S(1)-C(12)$ & $97.12(8)$ \\
\hline $\mathrm{N}(1)-\mathrm{C}(20)$ & $1.278(2)$ & $\mathrm{C}(11)-\mathrm{C}(12)-\mathrm{S}(1)$ & $112.64(12)$ \\
\hline$S(1)-C(12)$ & $1.810(18)$ & $C(13)-C(2)-S(1)$ & $109.82(12)$ \\
\hline$C(12)-C(13)$ & $1.537(2)$ & $C(20)-C(12)-S(1)$ & $106.92(12)$ \\
\hline$C(11)-C(12)$ & $1.5402)$ & $\mathrm{C}(13)-\mathrm{C}(12)-\mathrm{C}(11)$ & $110.44(14)$ \\
\hline \multicolumn{4}{|c|}{$5 a$} \\
\hline $\mathrm{N}(1)-\mathrm{C}(20)$ & $1.349(4)$ & $\mathrm{C}(12)-\mathrm{C}(11)-\mathrm{S}(1)$ & $109.1(2)$ \\
\hline $\mathrm{C}(21)-\mathrm{N}(1)$ & $1.414(4)$ & $\mathrm{O}(1)-\mathrm{C}(13)-\mathrm{C}(12)$ & $127.4(3)$ \\
\hline$S(1)-C(11)$ & $1.856(3)$ & $N(1)-C(20)-C(12)$ & $131.4(3)$ \\
\hline $\mathrm{C}(12)-\mathrm{C}(20)$ & $1.377(4)$ & C261)-S(1)-C(11) & $101.13(13)$ \\
\hline $\mathrm{C}(11)-\mathrm{C}(12)$ & $1.441(4)$ & $\mathrm{C}(20)-\mathrm{N} 1)-\mathrm{C}(21)$ & $133.5(2)$ \\
\hline $\mathrm{O}(1)-\mathrm{C}(13)$ & $1.235(4)$ & $\mathrm{C}(20)-\mathrm{C}(12)-\mathrm{C}(11)$ & $127.2(3)$ \\
\hline$C(26)-S(1)$ & $1.768(3)$ & $N(1)-C(20)-C(19)$ & $119.0(3)$ \\
\hline \multicolumn{4}{|c|}{6} \\
\hline$S(1)-C(1)$ & $1.819(19)$ & $\mathrm{C}(11)-\mathrm{N}(1)-\mathrm{C}(10)$ & $118.39(15)$ \\
\hline$C(1)-S(2)$ & $1.819(18)$ & $\mathrm{C}(2)-\mathrm{N}(2)-\mathrm{C}(22)$ & $118.05(16)$ \\
\hline $\mathrm{N}(2)-\mathrm{C}(2)$ & $1.279(2)$ & $C(16)-S(1)-C(1)$ & $95.13(9)$ \\
\hline$C(2)-C(3)$ & $1.474(2)$ & $\mathrm{C}(17)-\mathrm{S}(2)-\mathrm{C}(1)$ & $95.57(8)$ \\
\hline $\mathrm{N}(1)-\mathrm{C}(10)$ & $1.277(2)$ & $C(2)-C(1)-C(10)$ & $103.92(14)$ \\
\hline $\mathrm{N}(1)-\mathrm{C}(11)$ & $1.400(2)$ & $S(2)-C(1)-C(2)$ & $105.3(12)$ \\
\hline$C(1)-C(2)$ & $1.523(3)$ & $S(1)-C(1)-C(2)$ & $116.01(13)$ \\
\hline$C(1)-C(10)$ & $1.527(2)$ & $\mathrm{N}(2)-\mathrm{C}(2)-\mathrm{C}(1)$ & $126.97(15)$ \\
\hline $\mathrm{C}(10)-\mathrm{C}(9)$ & $1.459(3)$ & $S(2)-C(1)-S(1)$ & $113.32(9)$ \\
\hline $\mathrm{C}(22)-\mathrm{N}(2)$ & $1.408(2)$ & $\mathrm{N}(2)-\mathrm{C}(2)-\mathrm{C}(3)$ & $124.69(18)$ \\
\hline
\end{tabular}




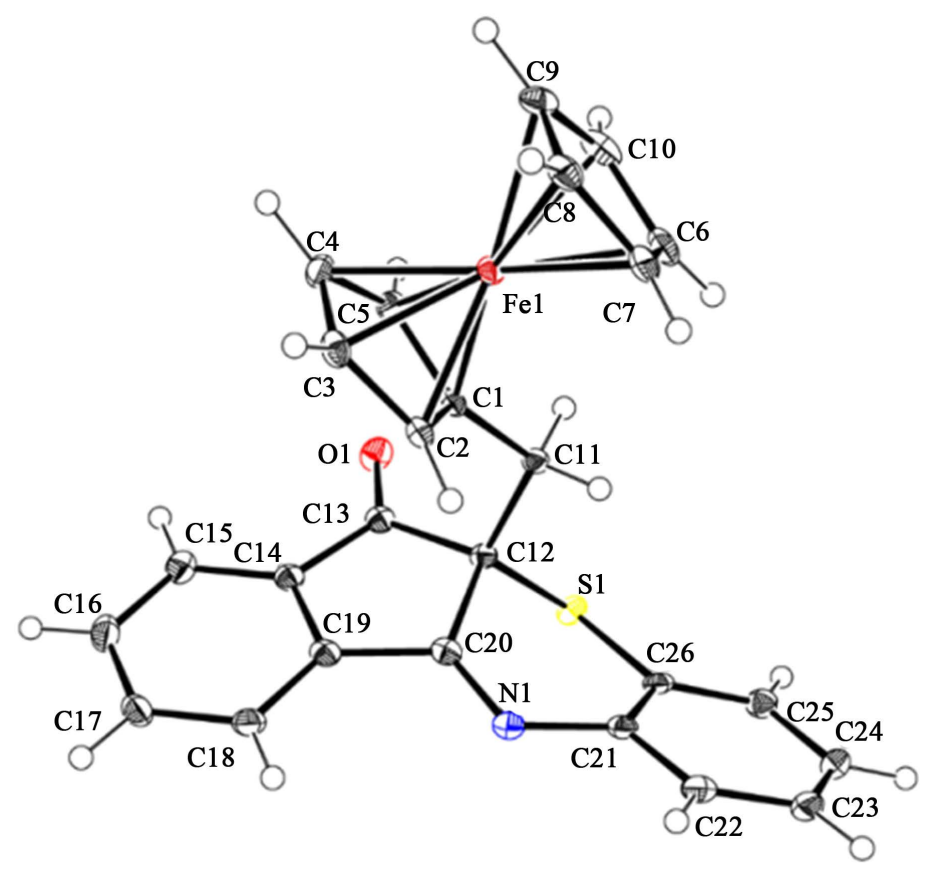

Figure 1. X-ray crystal structure of $4 \mathrm{a}$.

The ${ }^{1} \mathrm{H}$ NMR spectrum of $\mathbf{5 a}$ contains characteristic signals for one proton of the $\mathrm{CH}$ group in $\delta 5.41 \mathrm{ppm}$, one proton of the $\mathrm{NH}$ group in $\delta 4.26 \mathrm{ppm}$, one singlet for the protons of the unsubstituted $\mathrm{C}_{5} \mathrm{H}_{5}$ ring of one ferrocene $\delta 4.16$ ppm and multiplets for the eight protons of two $o-\mathrm{C}_{6} \mathrm{H}_{4}$ groups. The data from ${ }^{13} \mathrm{C}$ NMR spectroscopy of this compound are in full accord with the proposed structure. And X-ray diffraction analysis was performed on a single crystal grown by crystallization from dichloromethane. The general view of the molecule $5 \mathbf{a}$ is shown in Figure 2 and the main geometrical parameters are given in Table 1. Data from the X-ray analysis demonstrated that $\mathbf{5 a}$ is 2 -indeno [2,3b]2-ferrocenyl[1,5]benzo-2,5-dihydrothiazepine.

The structures of 2-ferrocenyl- and 2-p-anisylbenzothiazoles $3 a, b$ and indano[2,1-b:2,3-b] bis [ [1,4] benzothiazine6 were also confirmed by ${ }^{1} \mathrm{H}$ and ${ }^{13} \mathrm{C}$ NMR spectroscopy, mass spectrometry, and data from literature [17] [18] [19]. These facts confirm the assumed structures.

The spatial structure of single crystals of indano[2,1-b:2,3-b] bis[1,4] benzothiazine 6 prepared by crystallization from chloroform was determined by X-ray diffraction analysis (Figure 3). The principal geometric parameters of this molecule with a "three-petal" system of fused two six- and one five-membered rings and a quaternary carbon atom $\mathrm{C}(1)$ are listed in Table 1 . The bond lengths $\mathrm{C}(1)-\mathrm{S}(1)(1.8196 \AA)$, and $\mathrm{C}(1)-\mathrm{S}(2)(1.8191 \AA)$ are somewhat larger, and the $\mathrm{N}(1)-\mathrm{C}(1)(1.277 \AA)$ and $\mathrm{N}(2)-\mathrm{C}(1)(1.279 \AA)$ bond lengths are somewhat shorter than the standard values [24].

The results of this study indicate cyclocondensation reactions of 2-arylmethylidenindan-1,3-dione 1a,b with $o$-aminothiophenol2 and breakage of the $\mathrm{C} \alpha=\mathrm{C} \beta$ multiple bond [28] in the initial $\mathbf{1} \mathbf{a}, \mathbf{b}$ compounds subjected to the action of 1,4-bis-nucleophile 2 . In this regard, these interactions can be viewed as a step 


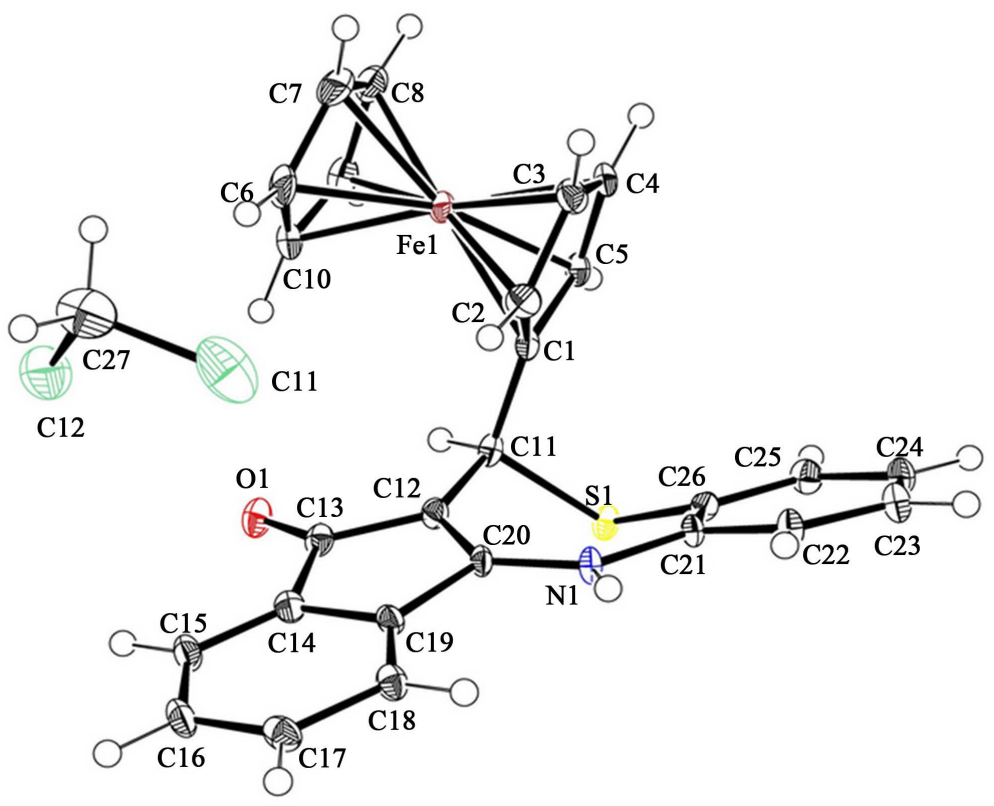

Figure 2. X-ray crystal structure of $5 \mathrm{a}$.

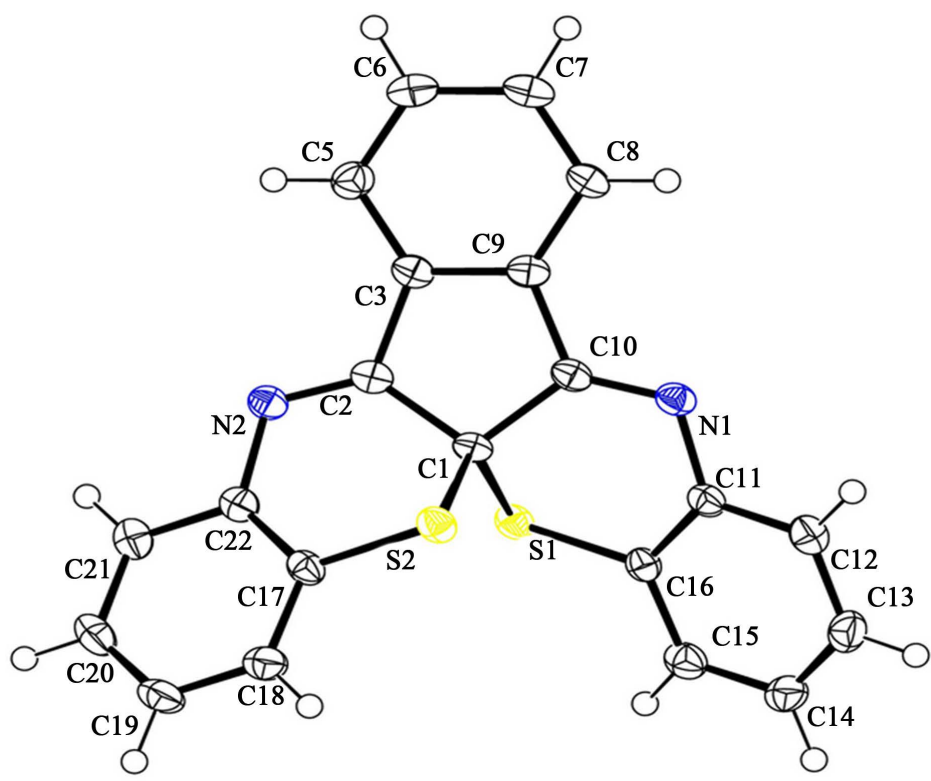

Figure 3. X-ray crystal structure of 6.

wise process consisting of several stages: 1) Michael addition of the molecule of a $o$-aminophenol 2 to substrates $1 \mathrm{a}, \mathrm{b}$ gave intermediates $7 \mathrm{a}, \mathrm{b} ; 2)$ Intramolecular cyclization of $7 \mathrm{a}, \mathrm{b}$ into tetracyclic thiazepines $5 \mathrm{a}, \mathrm{b} ; 3)$ Breaking of the $\sigma-\mathrm{C} \alpha-\mathrm{C} \beta$ bond in the addition intermediates 7a,b (Scheme 2); 4) "Anti- Michael" addition of $o$-aminophenol 2 to substrates $1 \mathrm{a}, \mathrm{b}$ gave intermediates $7 \mathrm{a}, \mathrm{b} ; 5)$ Intramolecular cyclization of $\mathbf{7 a}, \mathbf{b}$ into tetracyclic thiazines $4 \mathbf{a}, \mathbf{b}$ (Scheme 3 ).

To confirm the latter statement, we performed a specially aimed synthesis of compound 6, using indan-1,3-dione and $o$-aminothiophenol 2 as the initial substrates (Scheme 4). The products 6 and 8 were obtained in yields $\sim 41 \%$ and $34 \%$, respectively. 


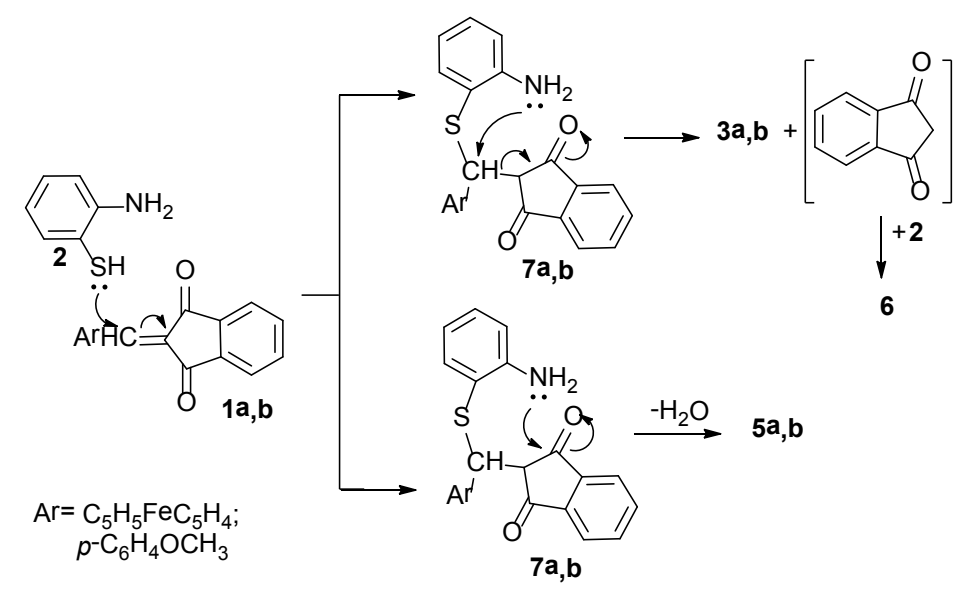

Scheme 2. The mechanism proposed for the process leading to indano[2,3b]-2-ferrocenylmethyl[1,4]benzothiazines and 2-indeno[2,3b]-2-ferrocenyl[1,5]benzo-2,5-dihydrothiazepines.

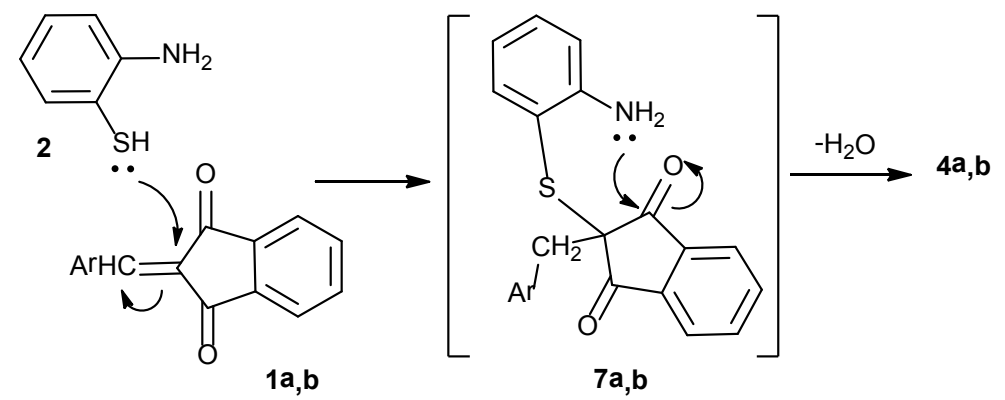

Scheme 3. Formation of the compounds $4 \mathrm{a}, \mathrm{b}$.

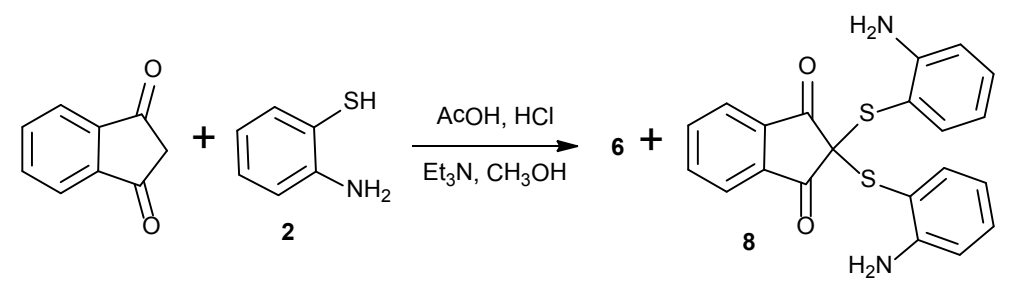

Scheme 4. Reaction of 1,3-indandione with 2-aminothiophenol 2.

\subsection{Cytotoxicity of the Benzothiazepines}

In this study, cytotoxicity assays of the four benzothiazepine compounds $4 \mathrm{a}, \mathrm{b}$ and $\mathbf{5 a , b}$ (Figure 4) were performed as described in the Experimental Section by using different cancer cell lines, including human glioblastoma (CNS U251), human prostatic adenocarcinoma (PC-3), human chronic myelogenous leukemia (K562), human colorectal adenocarcinoma (HCT-15), human mammary adenocarcinoma (MCF-7), and small cell lung cancer (SKLU) and the proteinbinding dye sulforhodamine B (SRB) assay in microculture to determine cell growth [24]. The initial cytotoxic screening data listen in Table 2, show excellent activities specifically toward K-562, HCT-15, and SKLU-1 tumor cell lines. From those data, we observe good values of cell growth inhibition, $4 \mathrm{~b}$ being the most active compound (Table 2). 


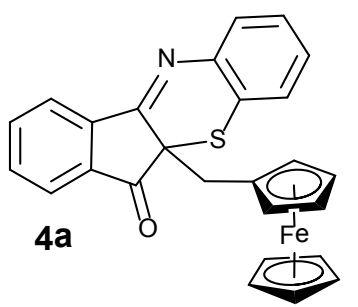<smiles>COc1ccc(CC23Sc4ccccc4N=C2c2ccccc2C3=O)cc1</smiles><smiles>O=C1C2=C(Nc3ccccc3SC2c2ccccc2)c2ccccc21</smiles><smiles>COc1ccc(C2Sc3ccccc3NC3=C2C(=O)c2ccccc23)cc1</smiles>

Figure 4. Variations in the structure of benzothiazepines.

Table 2. Inhibition of the Growth (\%) of Human Tumor Cell Lines for $4 \mathbf{a}, \mathbf{b}$ and $\mathbf{5 a}, \mathbf{b}$ at $25 \mu \mathrm{M}$ in $\mathrm{DMSO}^{\mathrm{a}}$.

\begin{tabular}{ccccccc}
\hline \multirow{2}{*}{ Compd } & \multicolumn{5}{c}{ \% of growth inhibition in Cell lines } \\
\cline { 2 - 7 } & U-251 & PC-3 & K562 & HCT-15 & MCF-7 & SKLU-1 \\
\hline 4a & $37.8 \pm 2.4$ & $36.0 \pm 7.7$ & $10.8 \pm 0.1$ & $30.9 \pm 3.9$ & $25.5 \pm 3.2$ & $37.2 \pm 2.2$ \\
4b & $77.8 \pm 5.8$ & $63.9 \pm 7.0$ & $>100$ & $90.2 \pm 4.9$ & $68.9 \pm 8.1$ & $>100$ \\
5a & $62.2 \pm 6.7$ & $78.3 \pm 9.4$ & $68.7 \pm 2.5$ & $61.4 \pm 9.5$ & $90.8 \pm 6.7$ & $71.3 \pm 4.8$ \\
5b & $48.6 \pm 5.1$ & $52.7 \pm 5.4$ & 8 co2.0 \pm 9.9 & $66.6 \pm 6.9$ & $68.4 \pm 7.4$ & $62.9 \pm 3.1$ \\
Cisplatin & $89.9 \pm 8.1$ & $86.7 \pm 4.1$ & $74.4 \pm 2.1$ & $81.8 \pm 7.1$ & $77.9 \pm 2.5$ & $95.8 \pm 2.1$ \\
\hline
\end{tabular}

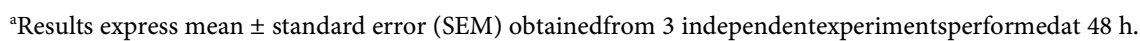

The results of the cytotoxic screening demonstrate that the presence of the substituent ferrocene for compounds $4 \mathrm{a}, 5 \mathrm{a}$ and anisole compounds $\mathbf{4 b}, \mathbf{5 b}$, have the influence in the cytotoxic activity disappears, obtaining good activity for (K562, HCT-15 and SKLU-1) tumor cell lines.

\section{Conclusion}

Reactions of 2-ferrocenyl- and 2-( $p$-methoxyphenyl) methylidenindandiones with 2-aminothiophenol in a $\mathrm{MeOH}$ medium in the presence of $\mathrm{AcOH} / \mathrm{HCl}$ gave novel indano[2,3b]-2-ferrocenyl-and 2-[(p-methoxyphenyl)methyl][1,4] benzothiazines 4a,b (products of "Anti-Michael”-addition/cyclization) and 2-indeno [2,3b]-2-ferrocenyl-and 2-(p-methoxyphenyl)[1,5]benzo-2,5-dihydrothiaze-pines $5 \mathrm{a}, \mathrm{b}$ respectively (products of Michael-addition/cyclization). These new compounds were obtained in $\sim 30 \%-45 \%$ yields. The reactions take place only via breakage of the $\operatorname{ArC} \alpha=\mathrm{C} \beta$ double bond with the formation of derivatives of arylcarbaldehydes (2-ferrocenyl- and 2-p-methoxyphenylbenzothiazoles 3a,b), as well as indandione (indano [2,1-b:2,3-b] bis[1,4]benzothiazine 6). The obtained 
compounds were structurally characterized by elemental analysis, $\mathrm{IR},{ }^{1} \mathrm{H}$ and ${ }^{13} \mathrm{C}$ NMR spectroscopy, mass-spectrometry, and single crystal X-ray diffraction analysis. The synthesized compounds $4 \mathrm{a}, \mathrm{b}$ and $\mathbf{5} \mathrm{a}, \mathrm{b}$ were evaluated for their in vitro anticancer activities against six human tumor cell lines: U-251, PC-3, K-562, HCT-15, MCF-7, SKLU-1. The compound 4b showed high activity against three tumoral cell lines (K-562, HCT-15 and SKLU-1).

\section{Acknowledgements}

This work was supported by the DGAPA (Mexico, grant IN 215015).

\section{References}

[1] Bariwal, J.B., Upadhyay, K.D., Manvar, A.T., Trivedi, J.C., Singh, J.S., Jain, K.S. and Shah, A.K. (2008) 1, 5-Benzothiazepine, a Versatile Pharmacophore: A Review. European Journal of Medicinal Chemistry, 43, 2279-2290.

https://doi.org/10.1016/j.ejmech.2008.05.035

[2] Hekmatshoar, R., Sadjadi, S., Shiri, S., Heravi, M.M. and Beheshtiha, Y.S. (2009) Green Protocol for Synthesis of 1,5-Benzodiazepines and 1,5-Benzothiazepines in the Presence of Nanocrystalline Aluminum Oxide. Synthetic Communications, 39, 2549-2259. https://doi.org/10.1080/00397910802657925

[3] Nardi, M., Cozza, A., Maiuolo, L., Oliverio, M. and Procopio, A. (2008) Ga (OTf) 3-Promoted Condensation Reactions for 1, 5-Benzodiazepines and 1, 5-Benzothiazepines. Tetrahedron Letters, 49, 5302-5308.

https://doi.org/10.1016/j.tetlet.2008.06.082

[4] Bl-Bayouki, K.A. (2013) Benzo[1,5]thiazephine: Synthesis, Reactions, Spectroscopy and Applications. Organic Chemistry International, 1, 1-71. https://doi.org/10.1155/2013/210474

[5] Nikalje, A.P. and Vyawahare, D. (2011) Facile Green Synthesis of 2,4-substituted2,3-dihydro-1,5 Benzothiazepine Derivatives as Novel Anticonvulsant and Central Nervous System (CNS) Depressant Agents. African Journal of Pure and Applied Chemistry, 5, 422-428.

[6] Pommier, Y., Garafalo, A., Brizzi, A., Campiani, G., Fiornini, I. and Nacci, V. (1999) Thiazolothiazepine Inhibitors of HIV-1 Integrase. Journal of Medicinal Chemistry, 42, 3334-3341.

[7] Upadhyay, K., Manvar, A., Rawal, K., Joshi, S., Trivedi, J., Chaniyara, R. and Shah, A. (2012) Evaluation of Structurally Diverse Benzoazepines Clubbed with Coumarins as Mycobacterium tuberculosis Agents. Chemical Biology \& Drug Design, 80, 1003-1008. https://doi.org/10.1111/j.1747-0285.2012.01436.x

[8] Arya, K. and Dandia, A. (2008) The Expedient Synthesis of 1,5-benzothiazepines as a Family of Cytotoxic Drugs. Bioorganic \& Medicinal Chemistry Letters, 18, 114119. https://doi.org/10.1016/j.bmcl.2007.11.002

[9] Singh, G., Kumar, N., Yadav, A.K. and Mishra, A.K. (2002) Syntheses of Some New 1,5-Benzothiazepine Derivatives and Their Ribofuranosides as Antimicrobial Agents. Heteroatom Chemistry, 13, 620-625. https://doi.org/10.1002/hc.10051

[10] Dandia, A., Singh, R., Singh, D., Laxkar, A. and Sivpuri, A. (2010) Regioselective Synthesis of Diltiazem Analogue Pyrazolo[4,3-c][1,5]benzothiazepines and Antifungal Activity. Phosphorus, Sulfur and Silicon, 185, 2472-2479. https://doi.org/10.1080/10426501003713064

[11] Ansari, F.I., Kalsoom, S., Zaheer-ul-Haq, Ali, Z. and Jabeen, F. (2012) In Silico Stu- 
dies on 2,3-dihydro-1,5-benzothiazepines as Cholinesterase Inhibitors. Medicinal Chemistry Research, 21, 2329-2339. https://doi.org/10.1007/s00044-011-9754-6

[12] Saini, R.K., Joshi, Y.C. and Joshi, P. (2008) Solvent-Free Synthesis of Some 1,5Benzothiazepines and Benzodiazepines and Their Antibacterial Activity. Phosphorus, Sulfur and Silicon, 183, 2181-2190. https://doi.org/10.1080/10426500701852661

[13] Kopf-Maier, P. and Kopf, H. (1987) Non-Platinum Group Metal Antitumor Agents. History, Current Status, and Perspectives. Chemical Reviews, 87, 1137-1152. https://doi.org/10.1021/cr00081a012

[14] Willy, B. and Müller, T.J.J. (2010) Three-Component Synthesis of benzo[b][1,5]thiazepines via Coupling-Addition-Cyclocondensation Sequence. Molecular Diversity, 14, 443-453. https://doi.org/10.1007/s11030-009-9223-Z

[15] Klimova, M.A., Gallardo Vega, J.J., Sánchez García, M., Flores-Alamo, J.M. and Méndez Stivalet, J. (2015) 4-Aryl-2-ferrocenyl- and 2-Aryl-4-ferrocenyl2,3-dihydro-1,5-benzothiazepines with Potentially Biological Activities: Synthesis, Characterization, X-ray Diffraction Studies. Journal of Heterocyclic Chemistry, ID JHET-15-0038. https://doi.org/10.1002/jhet.2519

[16] Katritzky, A.R., Odens, H.H. and Zhang, S. (2001) Novel Syntheses of 2,3-Dihydro-1,5-benzothiazepin-4 $(5 \mathrm{H})$-ones and $2 \mathrm{H}-1,4$-Benzothiazin-3(4H)-ones. The Journal of Organic Chemistry, 66, 6792-6796. https://doi.org/10.1021/jo0101959

[17] Šališova, M., Prokešova, M., Kubrikanova, M. and Toma, Š. (1993) Reactions of Ferrocenecarboxylic Acid and Omega Ferrocenyl-Omega-Oxoalkanoic Acids with 2-Aminothiophenol. Chemical Papers-Chemicke Zvesti, 47, 183-185.

[18] Arslan, H. and Algül, Ö. (2007) Synthesis and Ab Initio/DFT Studies on 2(4-methoxyphenyl)benzo[d]thiazole. International Journal of Molecular Sciences, 8, 760-776. https://doi.org/10.3390/i8080760

[19] Roth, H.J. and Kok, W. (1976) Zur Kenntnis der Ninhydrin-Reaktion, 3. Mitt. Reaktion mit Dimethoxyanilinen und reaktiven Aromaten. Archiv der Pharmazie, 309, 81-86. https://doi.org/10.1002/ardp.19763090202

[20] CrysAlis, C.C.D. and CrysAlis, R. (2009) Crystal Structure Solution. Oxford Difraction, Abingdon.

[21] Sheldrick, G.M. (1990) SHELXS-97, Crystal Structure Solution. University of Göttingen, Göttingen.

[22] Sheldrick, G. (1997) M.SHELXS-97, Crystal Structure Refinament. University of Göttingen, Göttingen.

[23] Monks, A., Scudiero, D., Skehan, P., Shoemaker, R., Paul, K., Vistica, D., Hose, C., Langley, J., Cronise, P., Vaigro-Wolff, A., Gray-Goodrich, M., Campbell, H., Mayo, J. and Boyd, M. (1991) Feasibility of a High-Flux Anticancer Drug Screen Using a Diverse Panel of Cultured Human Tumor Cell Lines. Journal of the National Cancer Institute, 83, 757-766. https://doi.org/10.1093/jnci/83.11.757

[24] Eicher, S. Hauptmann, A. Speicher, (2012) The Chemistry of Heterocycles. Structures, Reactions, Synthesis and Applications. Wiley-VCH Verlag GmbH \& Co. KGaA, Weinheim, 529-545.

[25] Stankovič, E., Elečko, P. and Toma, Š. (1996) Knoevenagel Condensation of Ferrocenecarbaldehyde with Some Methylene Active Reagents on Inorganic Supports. Chemical Papers, 50, 68-71.

[26] Cooke, G., Palmer, H.M. and Schulz, O. (1995) Novel Ferrocene Derivatives From Precursors Derived From Alumina-Catalysed Knoevenagel Reactions of Ferrocenecarboxaldehyde. Synthesis, 1995, 1415-1418. https://doi.org/10.1055/s-1995-4125

[27] Wu, D., Ren, Z., Cao, W. and Tong, W. (2005) Solvent-Free Synthesis of 2-Aryli- 
deneindan-1,3-diones in the Presence of Magnesium Oxide or Silica Gel Under Grinding. Synthetic Communications, 35, 3157-3162.

https://doi.org/10.1080/00397910500282968

[28] Sánchez García, J.J., Gallardo Vaga, M.A., Flores-Álamo, M., Méndez Stivalet, J.M. and Klimova, E.I. (2015) 1,4-dinitrogen Nucleophiles in the Breaking of the $\mathrm{C} \alpha=\mathrm{C} \beta$ Multiple Bond in 2 -ferrocenylmethylidene- $\beta$-dicarbonyl Compounds. Simple Method for the Preparation of the $\mathrm{Al}(\mathrm{III})$ Complexes with $\beta$-diketones and $\beta$-ketoesters. Journal of Applied Chemical Science International, 2, 147-158. 


\section{Supplementary Material}

The crystallographic data for $4 \mathrm{a}, 5 \mathrm{a}$ and $\mathbf{6}$ have been deposited with the Cambridge Crystallographic Data Centre as supplementary publication under the CCDC numbers 1423550, 1423551 and 1423552. These data can be obtained free of charge from the Cambridge Crystallographic Data Centre, 12, Union Road, Cambridge DB2 1EZ, UK; Fax: (internat.) +44-1223/336-033; E-mail: deposit@ccdc.cam.ac.uk].

For general information, all experimental data and copies of the NMR spectra and UV/V are Spectra.

The $1 \mathrm{H}$ and 13C NMR spectra were recorded on a Unity Inova Varian spectrometer $(300$ and $75 \mathrm{MHz}$ ) for solutions in $\mathrm{CDCl} 3$ with $\mathrm{Me} 4 \mathrm{Si}$ as the internal standard. The IR spectra were measured with an FTIR spectrophotometer (Spectrum RXI Perkin-Elmer instruments) using $\mathrm{KBr}$ pellets. The mass spectra were obtained on a Varian MAT CH-6 instrument (EI MS, 70 eV). Elementar Analysensysteme LECO CHNS-900 was used for elemental analyses.

Compound 3a "2-Ferrocenylbenzothiazole"

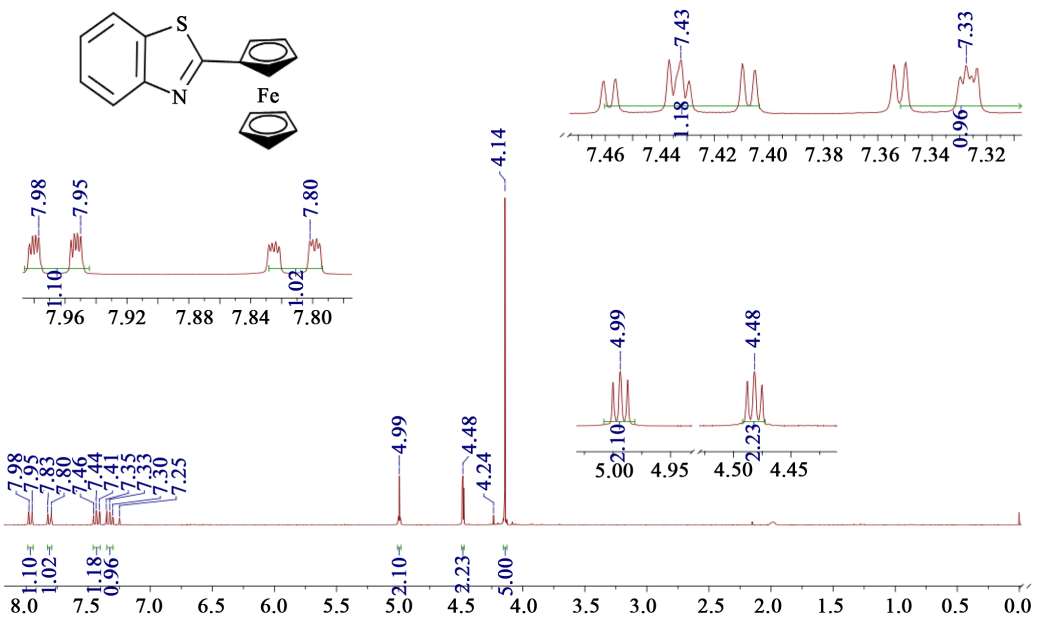

Figure S1. 1H NMR (300 MHz, CDCl3, TMS) spectrum of compound 3a.

\section{Compound 3b "2-(p-Methoxyphenyl)benzothiazole "}
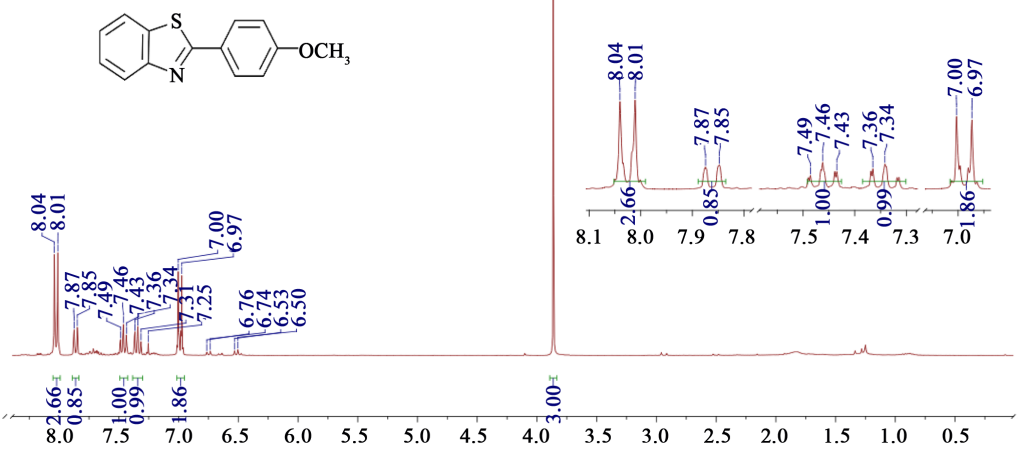

Figure S2. 1H NMR (300 MHz, CDCl3, TMS) spectrum of compound 3b. 


\section{Compound 4a "Indano[2,3b]-2-ferrocenylmethyl[1,4]benzothiazine"}

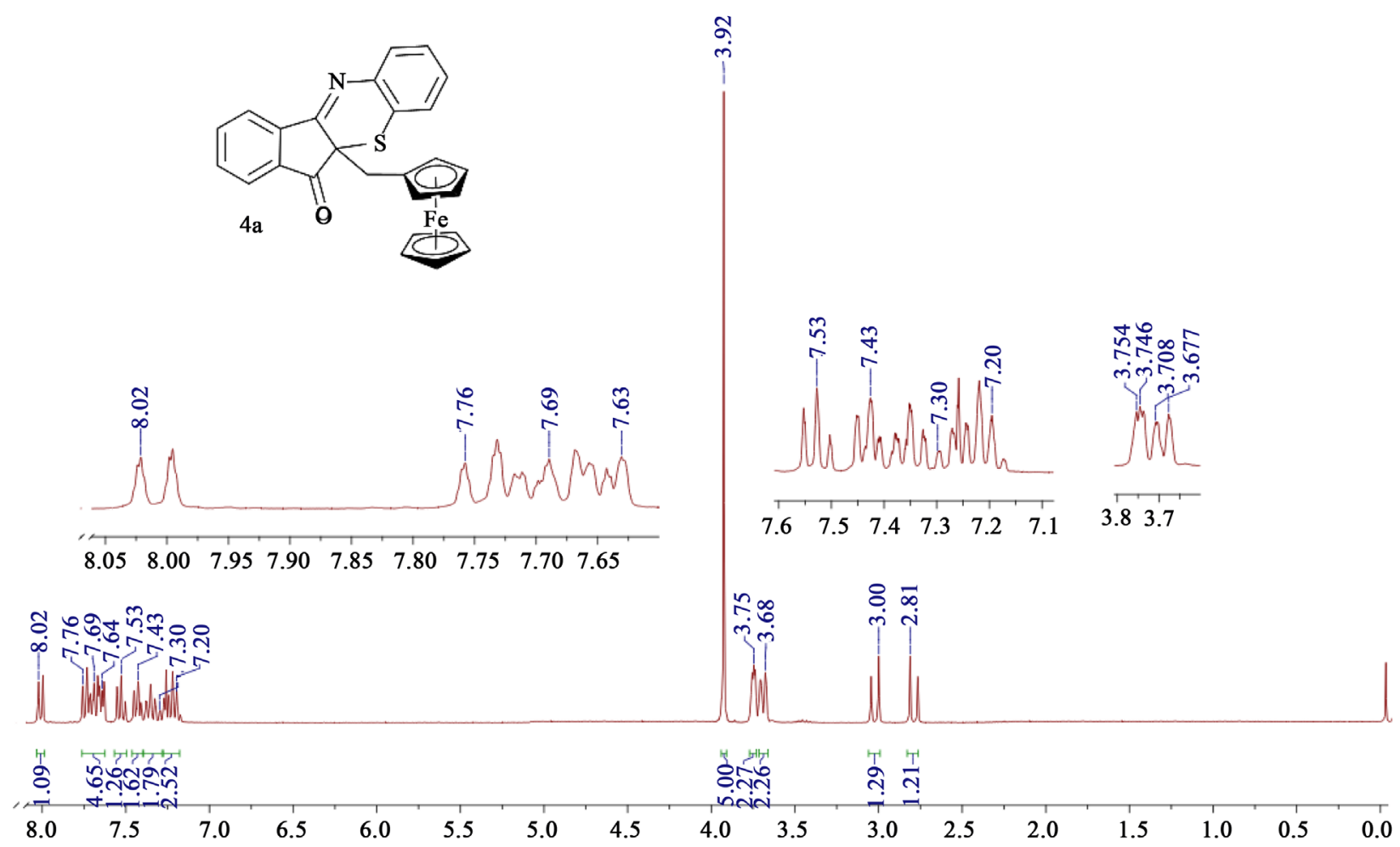

Figure S3. 1H NMR (300 MHz, CDCl3, TMS) spectrum of compound 4a.
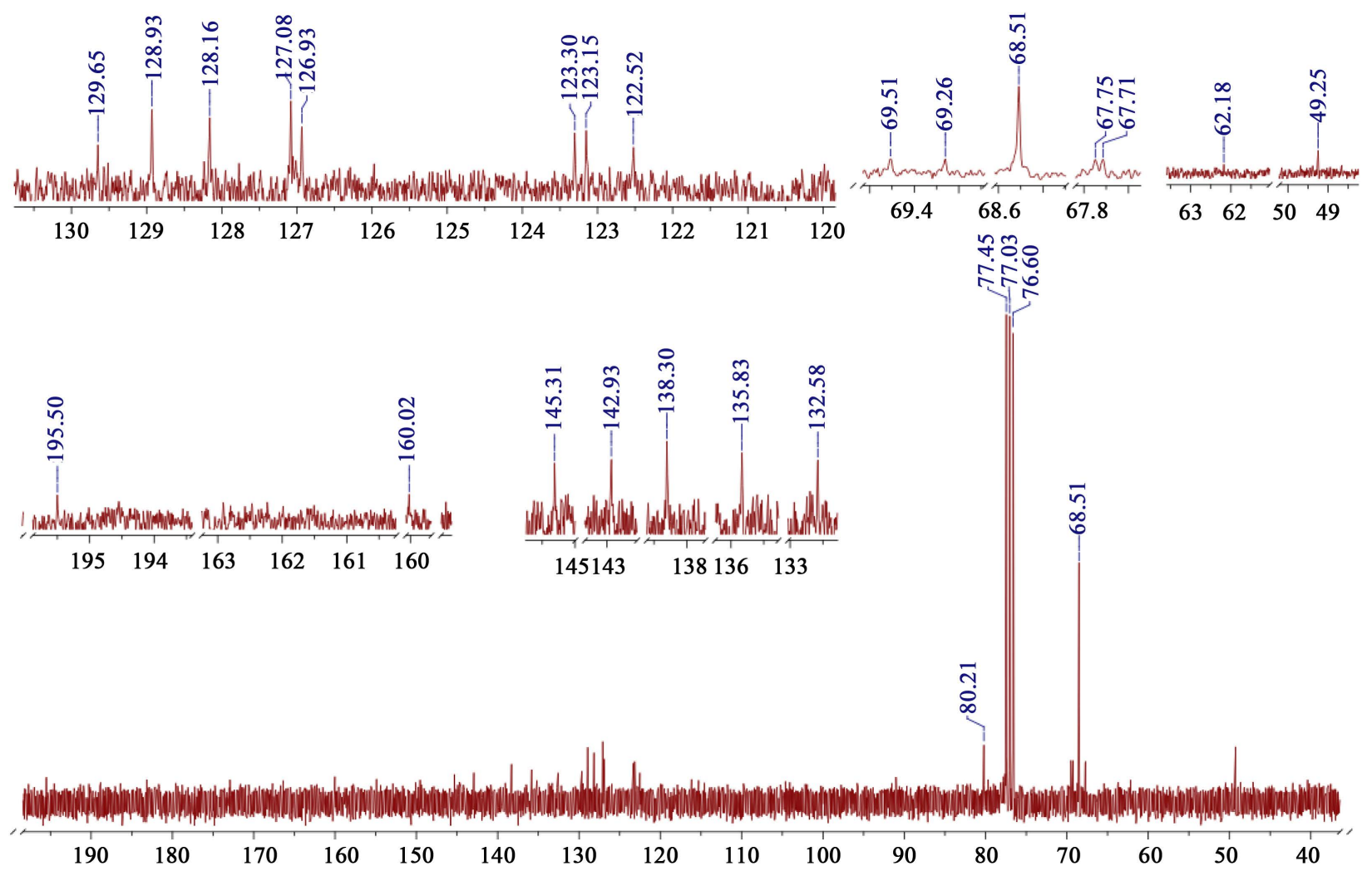

Figure S4. 13C NMR (75 MHz, CDCl3, TMS) spectrum of compound 4a. 


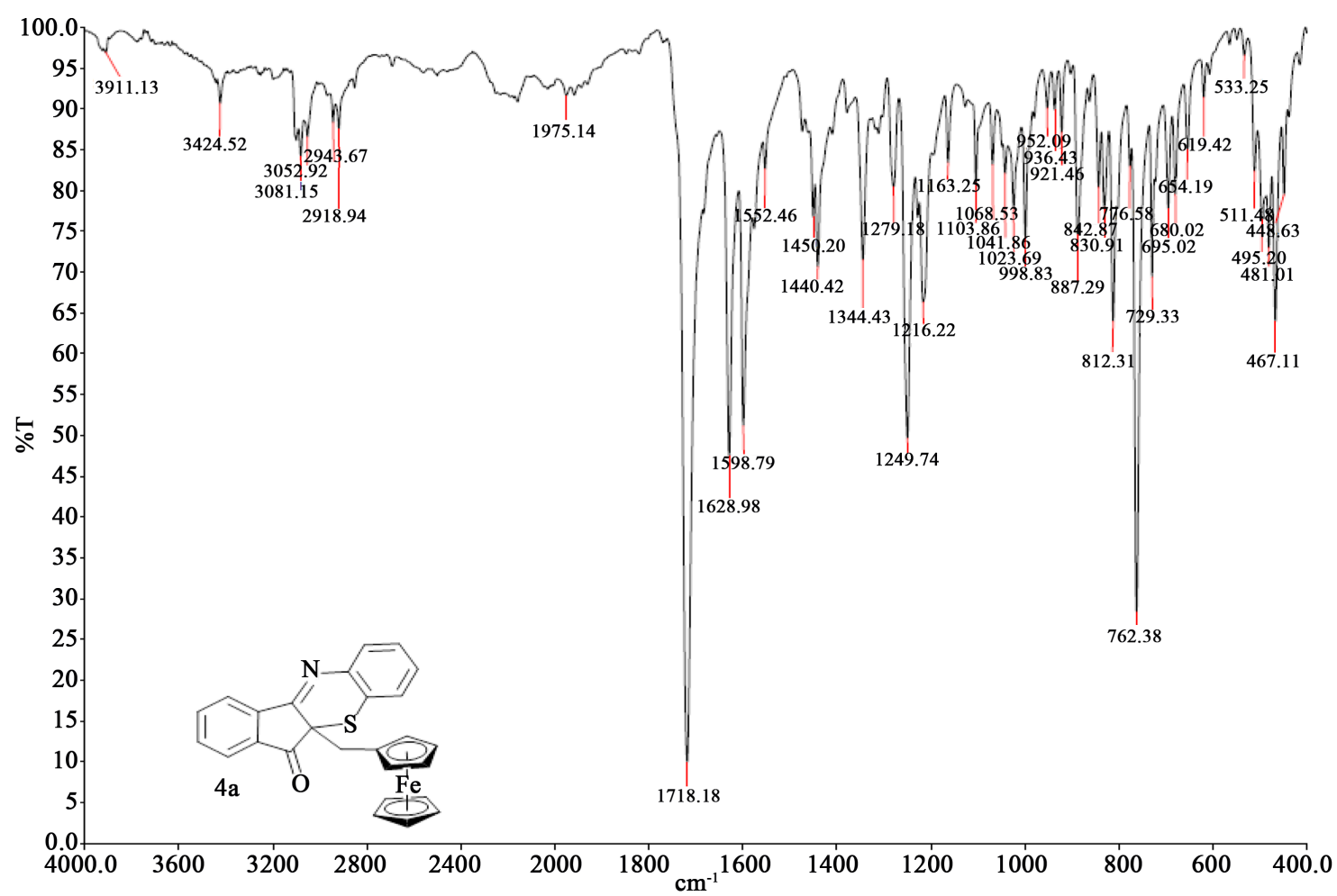

Figure S5. IR (KBr) spectrum of compound $4 a$.

MS (EI, $70 \mathrm{eV}$ ): m/z 449 [M]

D:IXcaliburldata|USAIIID $\backslash K E-86 \_1 \_1$

szComment

KE-86_1_1 \#19-20 RT: 1.61-1.72 RT: 2 NL: 1.15E7

T: +c EI Full ms [49.50 - 800.50]

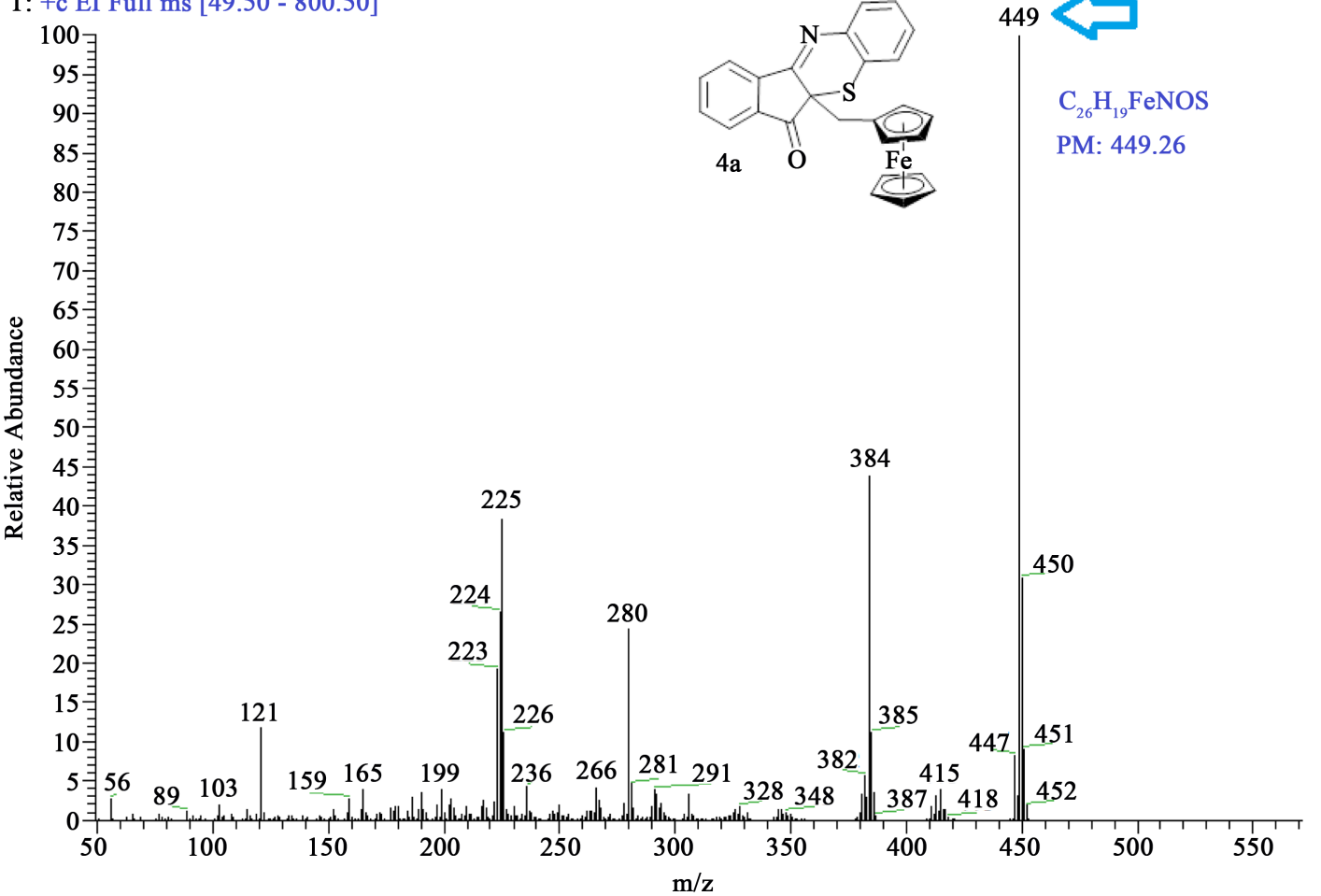

Figure S6. Mass Spectrometry spectrum of compound 4a. 
Compound $4 \mathrm{~b}$ Indano[2,3b]-2-[(p-methoxyphenyl) methyl][1,4]benzothiazine

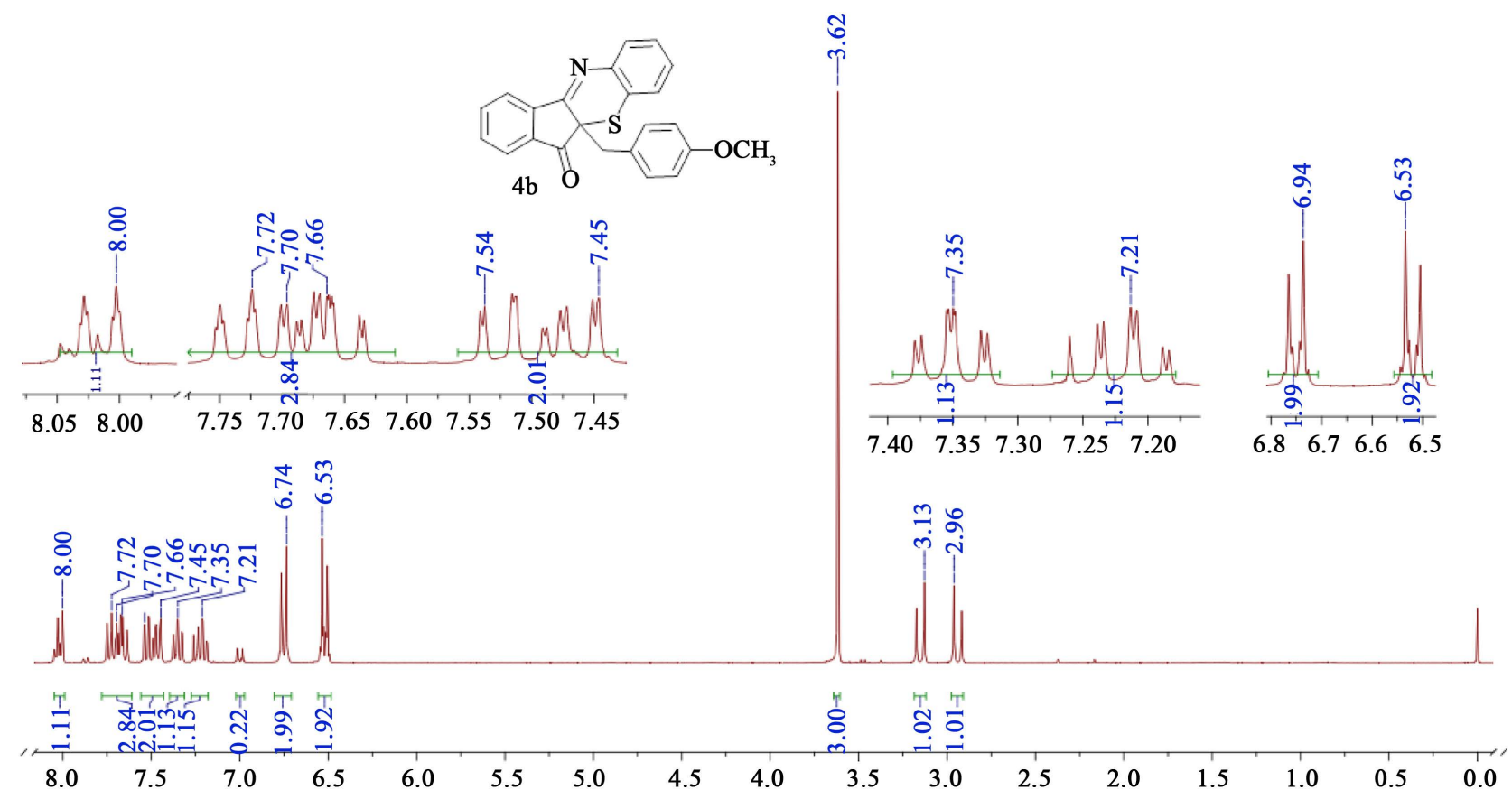

Figure S7. 1H NMR (300 MHz, CDCl3, TMS) spectrum of compound $4 \mathrm{~b}$.

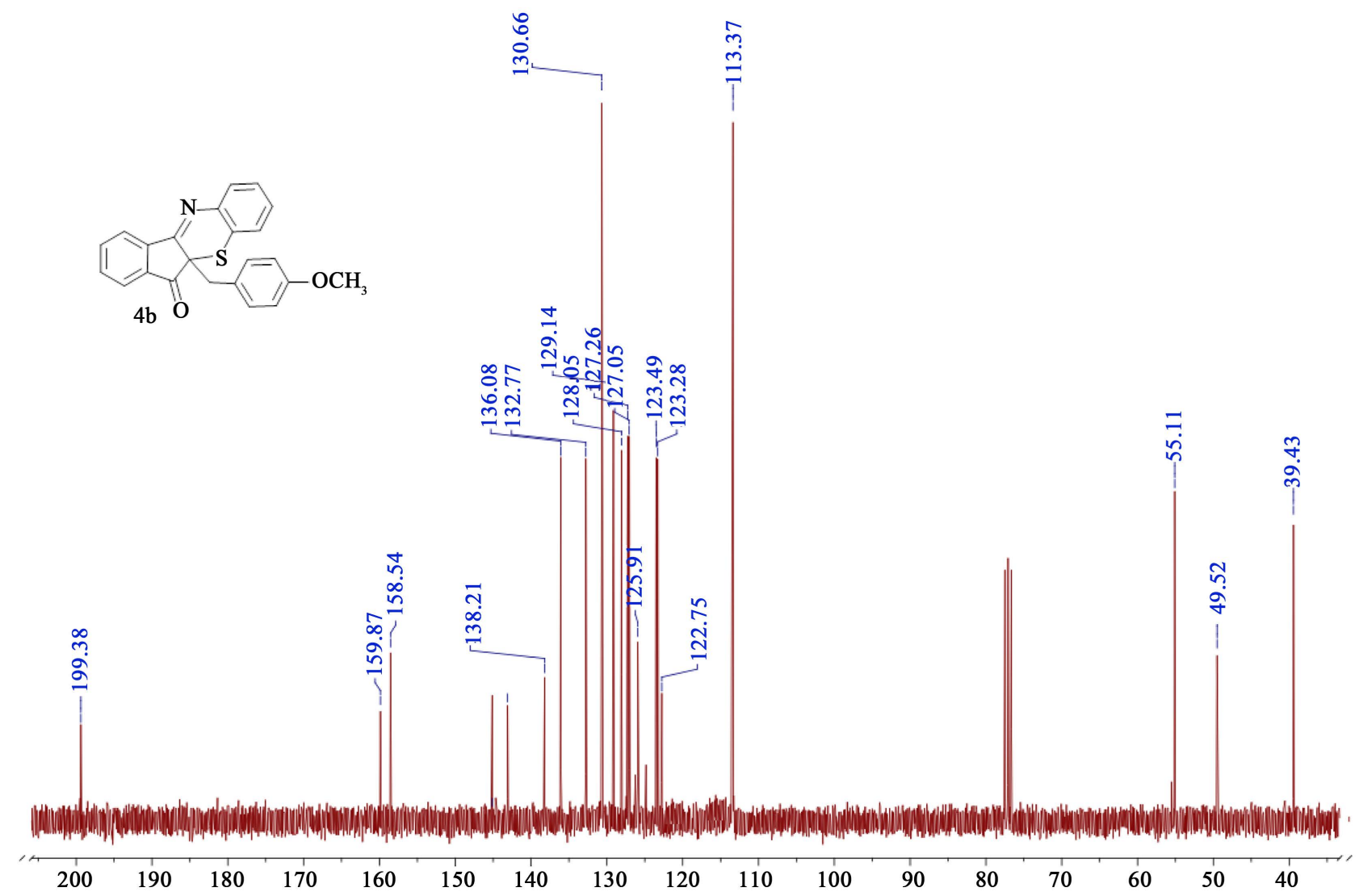

Figure S8. 13C NMR (75 MHz, CDCl3, TMS) spectrum of compound 4 b. 


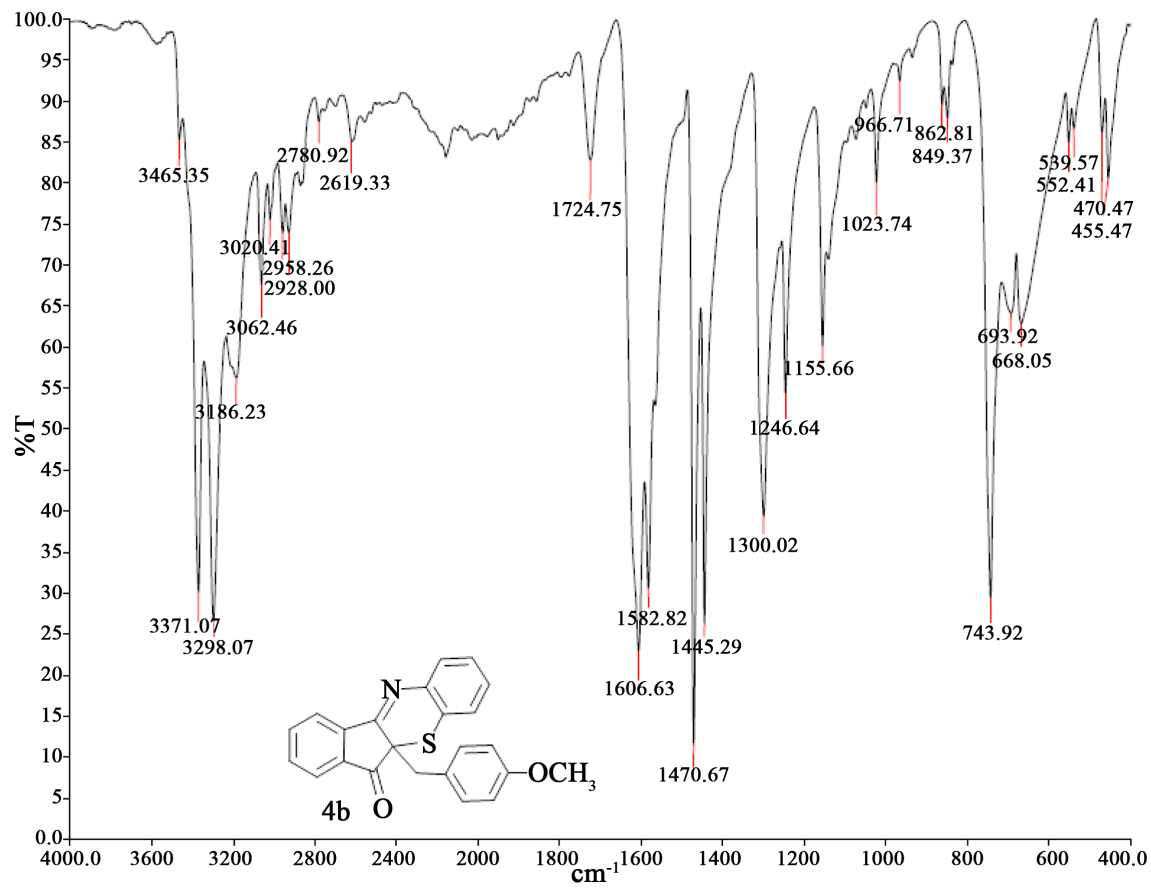

Figure S9. IR (KBr) spectrum of compound $\mathbf{4 b}$.

MS (EI, $70 \mathrm{eV}): \mathrm{m} / \mathrm{z} 449[\mathrm{M}]^{+}$

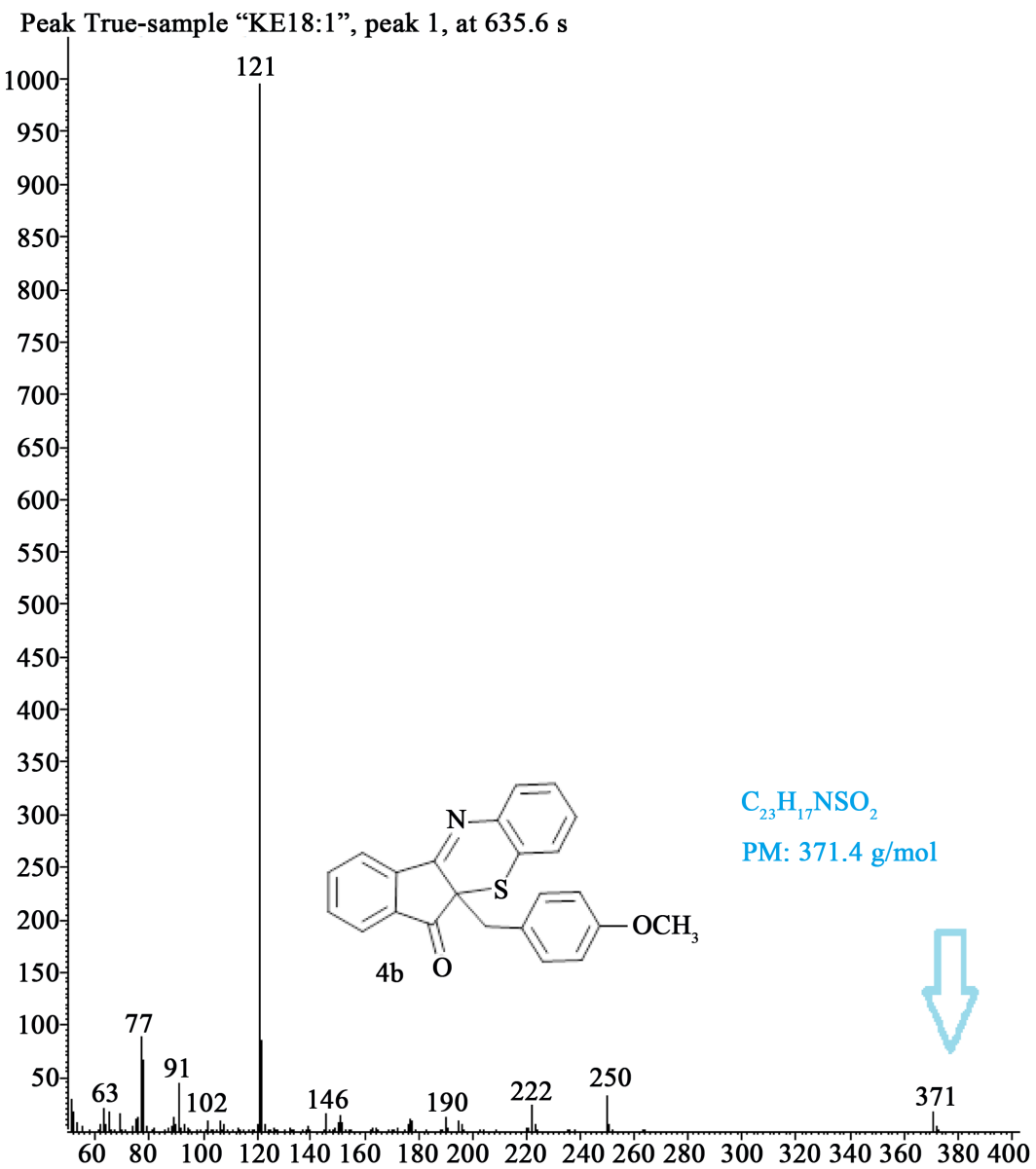

Figure S10. Mass Spectrometry spectrum of compound $\mathbf{4 b}$. 
Compound 5a 2-Indeno[2,3b]-2-ferrocenyl[1,5]benzo- 2,5-dihydrothiazepine

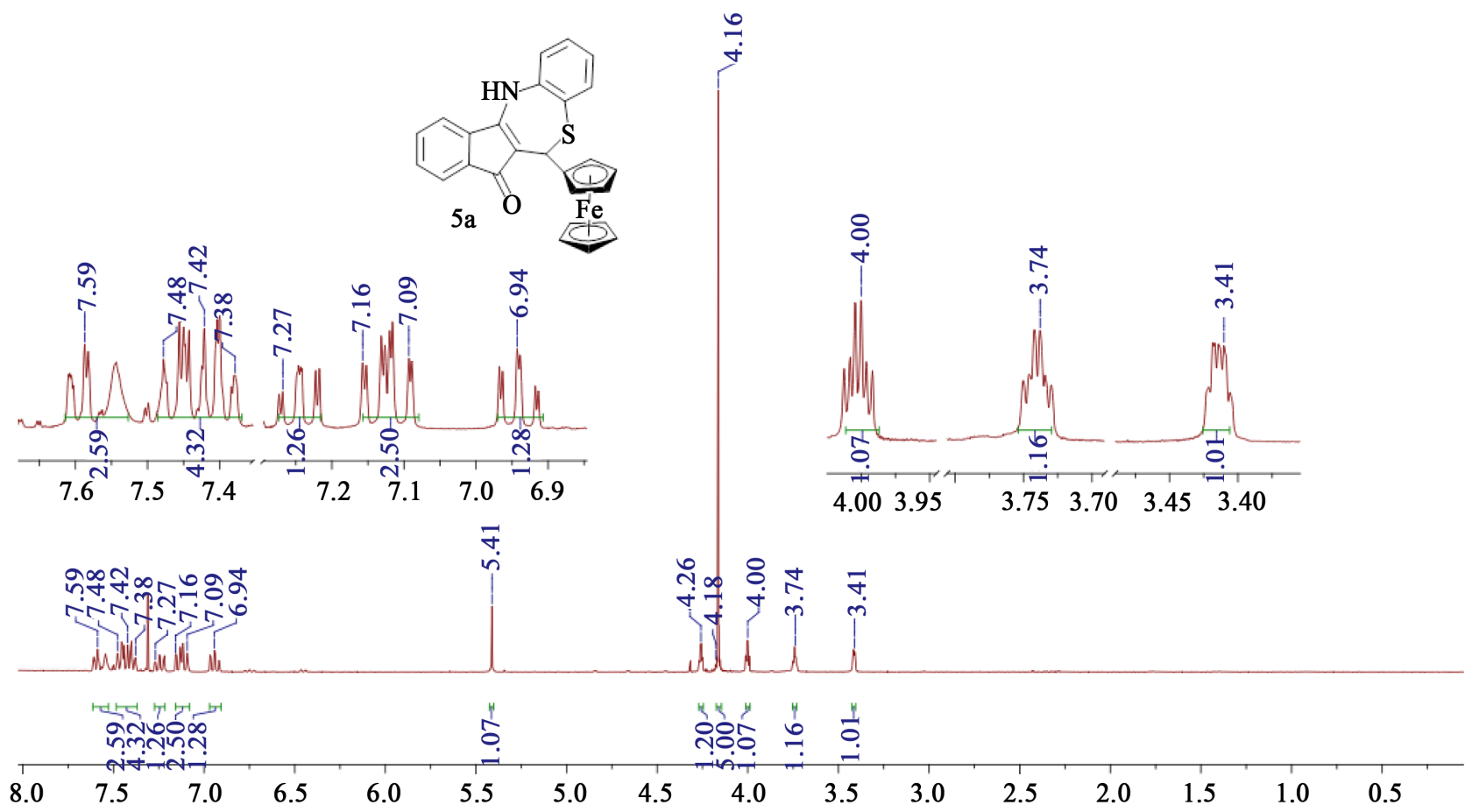

Figure S11. 1H NMR (300 MHz, CDCl3, TMS) spectrum of compound 5a.
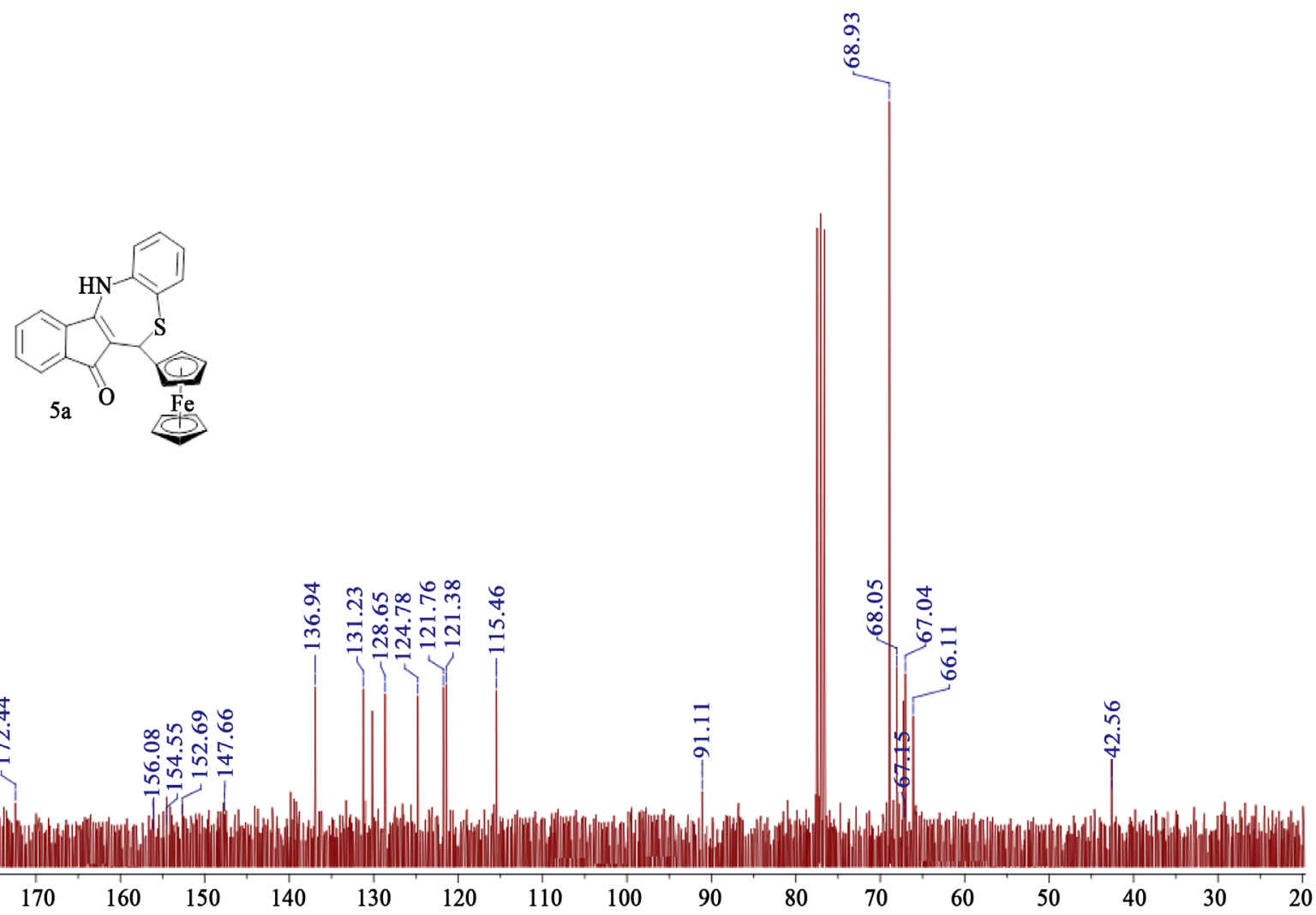

Figure S12. 13C NMR (75 MHz, CDCl3, TMS) spectrum of compound 5a. 


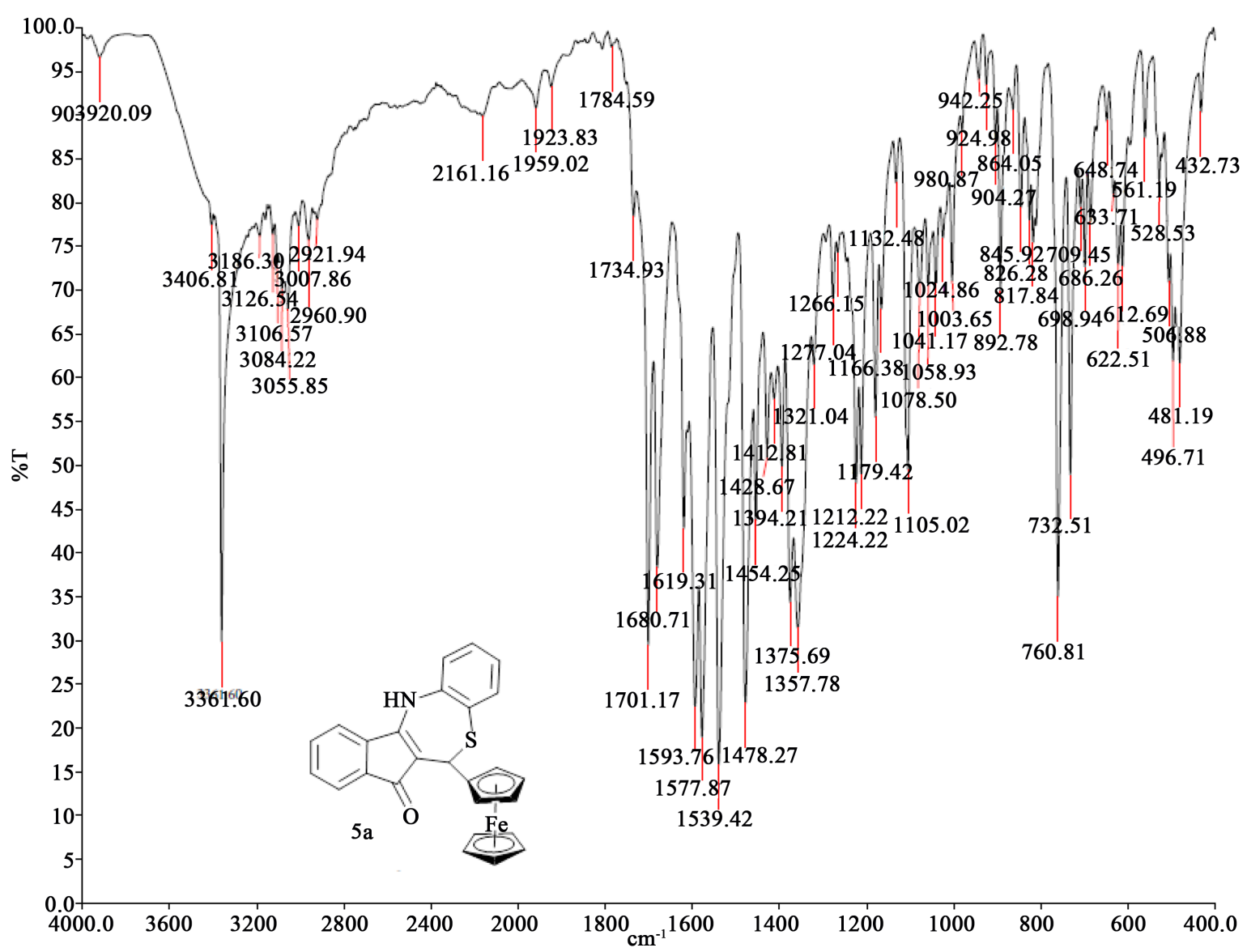

Figure S13. IR (KBr) spectrum of compound 5a.

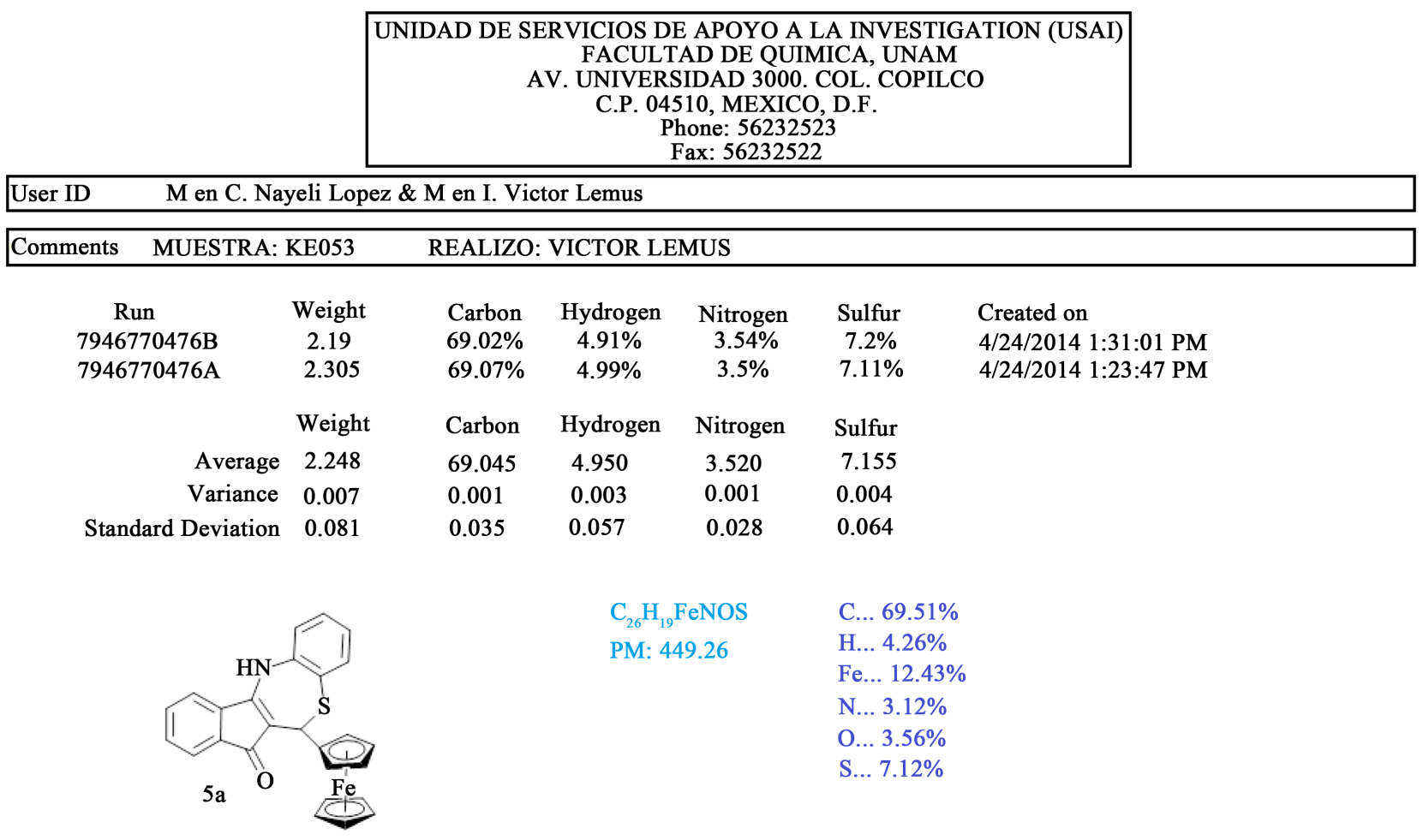

Figure S14. Elemental Analysis spectrum of compound 5a. 
D:IXcaliburldata|USAIIID|KE680914 11

szComment

KE680914_1_1 \#12 RT: 1.32 AV: 1 NL: 1.30E6

T: +c EI Full ms [32.50 - 800.50]

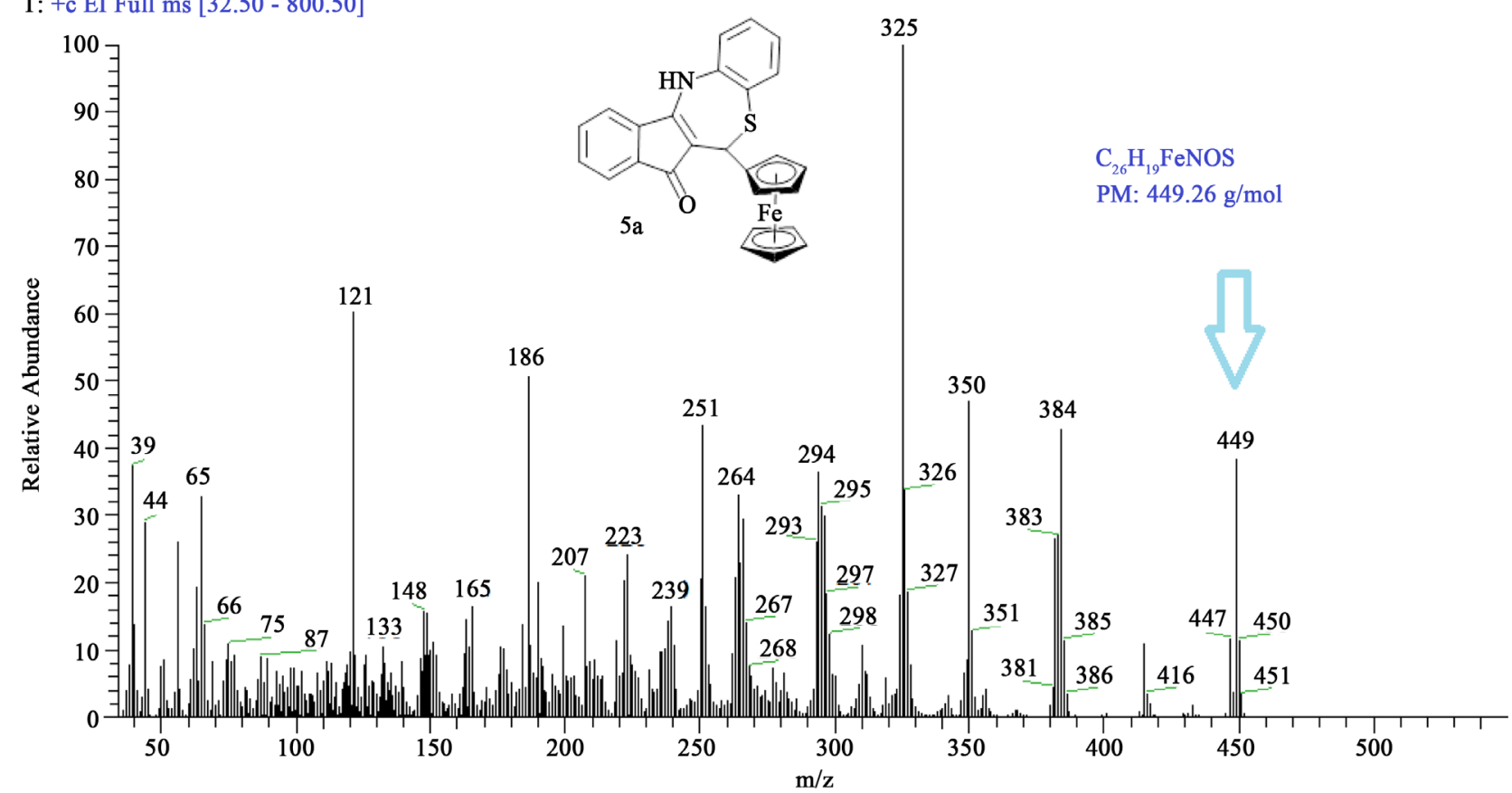

Figure S15. Mass Spectrometry spectrum of compound 5a.

Compound 5b 2-Indeno[2,3b]-2-(p-methoxyphenyl)[1,5]benzo-2,5-dihydrothiazepine

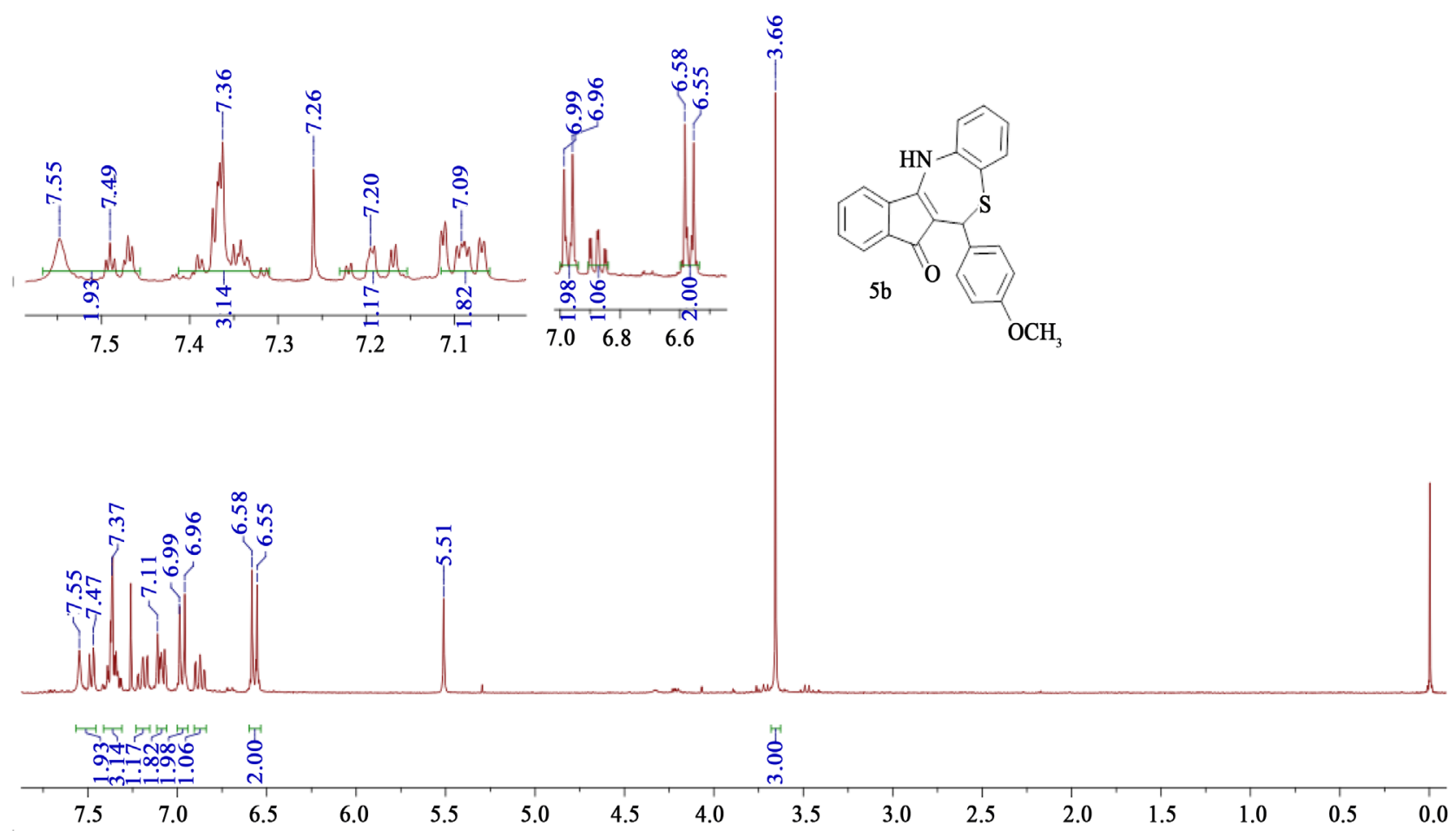

Figure S16. 1H NMR (300 MHz, CDCl3, TMS) spectrum of compound 5b. 

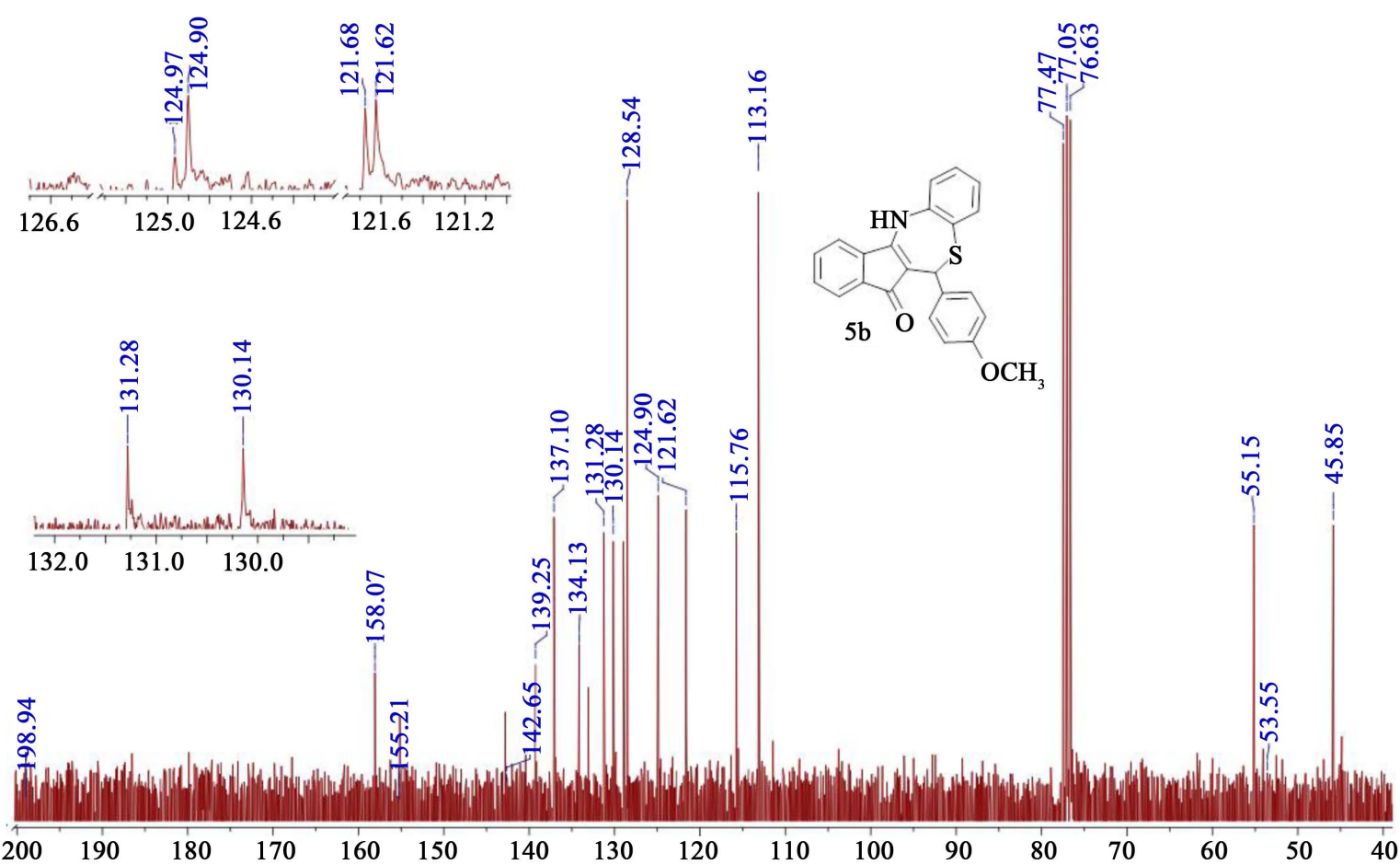

Figure S17. 13C NMR (75 MHz, CDCl3, TMS) spectrum of compound $\mathbf{5 b}$.

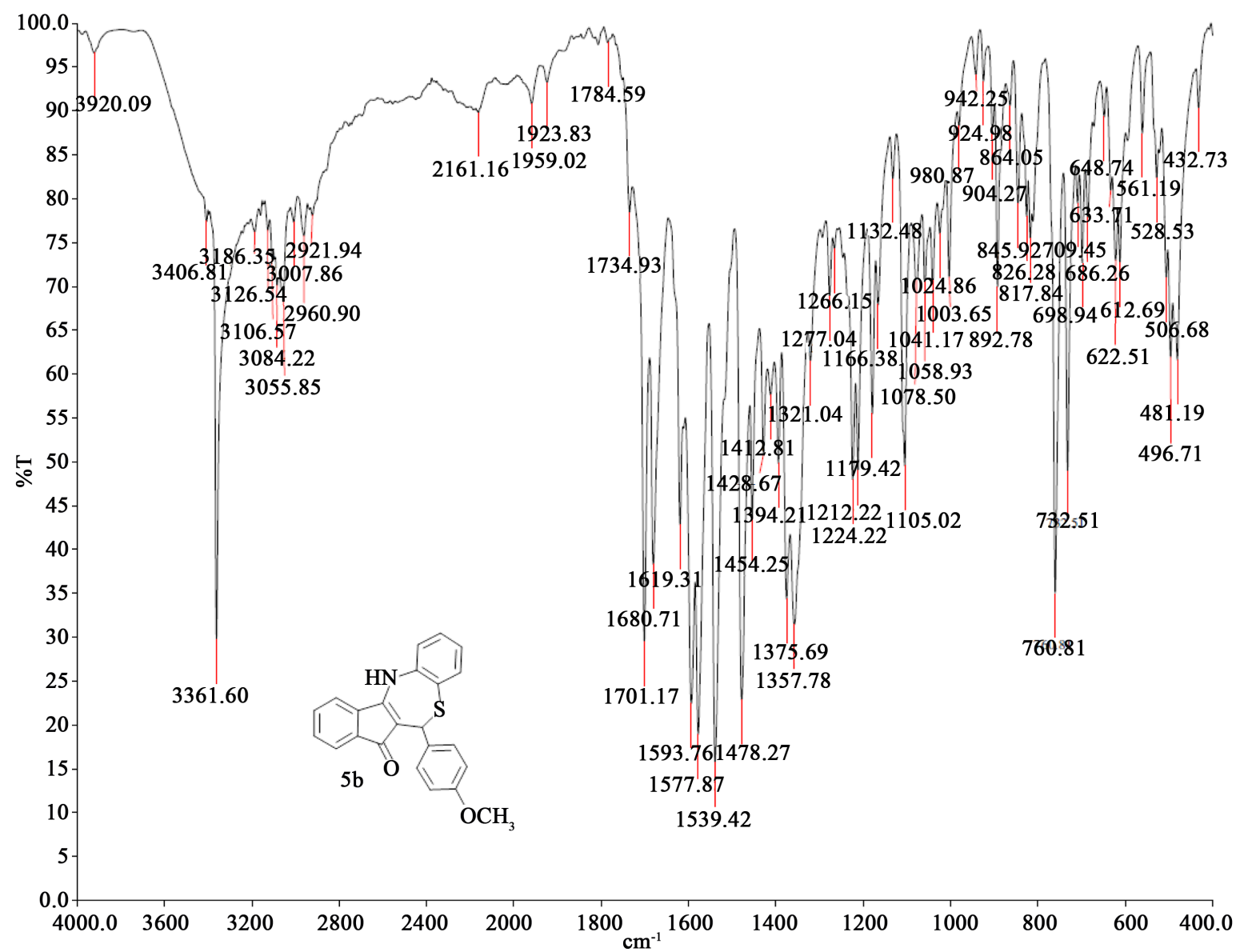

Figure S18. IR ( $\mathrm{KBr})$ spectrum of compound $\mathbf{5 b}$. 


\section{Compound 6 Indano[2,1-b:2,3-b]bis[[1,4]benzothiazine}

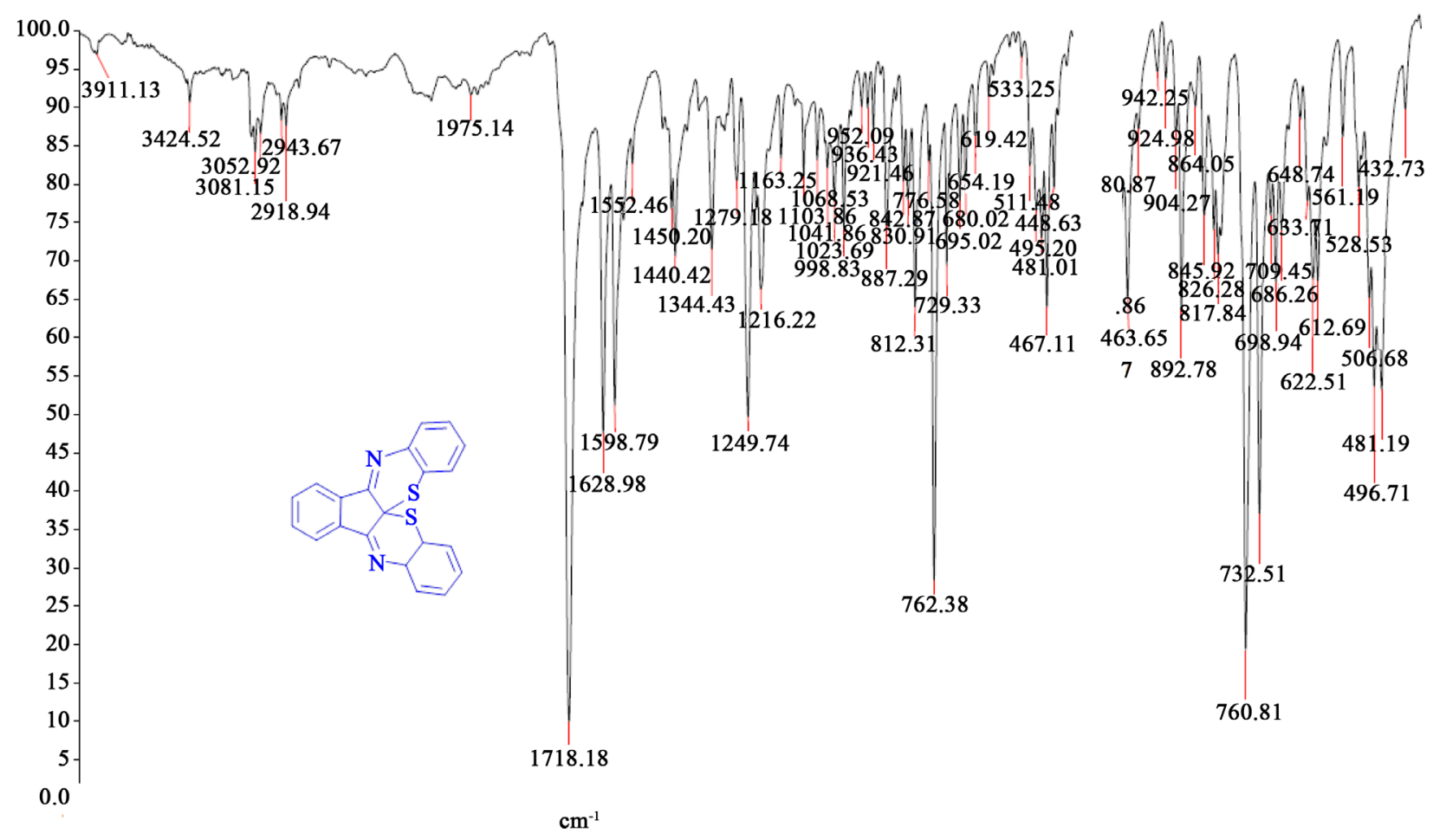

Figure S19. IR (KBr) spectrum of compound 6.

Submit or recommend next manuscript to SCIRP and we will provide best service for you:

Accepting pre-submission inquiries through Email, Facebook, LinkedIn, Twitter, etc. A wide selection of journals (inclusive of 9 subjects, more than 200 journals)

Providing 24-hour high-quality service

User-friendly online submission system

Fair and swift peer-review system

Efficient typesetting and proofreading procedure

Display of the result of downloads and visits, as well as the number of cited articles Maximum dissemination of your research work

Submit your manuscript at: http://papersubmission.scirp.org/

Or contact ijoc@scirp.org 